\title{
El final del Hierro Antiguo en el SE ibérico: CONTEXTOS CERÁmicos DE TRANSICIÓN PROCEDENTES DEL ASENTAMIENTO DE LOS CASAREJOS (Lorca, Murcia)
}

The end of Early Iron Age in the Iberian SE: transition pottery assemblages from Los Casarejos settlement (Lorca, Murcia)

\section{BENJAMÍN CUTILLAS VICTORIA B}

Grupo de Investigación en Arqueología (E041-02). Universidad de Murcia. benjamin.cutillas@um.es

\section{RESUMEN:}

En la segunda mitad del s. VI a.C., las comunidades del SE ibérico se ven inmersas en un profundo período de reestructuración territorial, con abandonos y procesos de contracción urbana que retratan las inestabilidades del período. Sin embargo, el núcleo de Los Casarejos se ocupa durante este momento en una posición poco apta y alejada de las principales rutas de comunicación de la región. En este artículo se presenta la revisión de la intervención realizada en este yacimiento, tanto en lo relativo a su secuencia cronoestratigráfica como sobre sus contextos cerámicos. Los resultados obtenidos han permitido recuperar nuevos datos a nivel material y territorial a partir de los que analizar las dinámicas que llevaron a la creación de este asentamiento monofásico, reconociendo además patrones y estrategias de ocupación complementarias que retratan la complejidad del período de transición entre el final del Hierro Antiguo y la emergencia de la cultura ibérica.

Palabras clave: SE ibérico, Edad del Hierro, asentamientos, vajillas cerámicas, dinámicas territoriales.

\begin{abstract}
:
In the second half of the 6th century BC, the communities of the Iberian SE were immersed in a deep period of territorial restructuring, with abandonment and processes of urban contraction that reflect the instabilities of the period. However, the site of Los Casarejos was occupied at this phase of transition in an unsuitable position, far from the main communication routes in the region. This work presents a review of the archaeological excavation carried out at this site, both in terms of its chronostratigraphic sequence and its ceramic assemblage. The results obtained have made it possible to recover new material and territorial data from which to analyse the dynamics that led to the creation of this single-phase settlement, also recognising complementary occupation patterns and strategies that point to the complexity of the transition period between the end of the Early Iron Age and the emergence of Iberian culture.
\end{abstract}

Key words: Iberian Southeast, Iron Age, settlements, ceramic assemblage, territorial dynamics. 
Dentro de los diversos fenómenos históricos que se dan en el SE de la península Ibérica durante el Ier milenio a.C., la transición entre el final del Hierro Antiguo y los inicios del período Ibérico continúa siendo uno de los peor conocidos. En una horquilla cronológica que se prolongó aproximadamente desde la segunda mitad del s. VI a mediados del V a.C., se sucedieron importantes procesos de reestructuración poblacional que afectaron tanto a las comunidades del corredor prelitoral del Segura-Guadalentín (González Prats 1983; Ros 1989; Cutillas y Ros 2020; Lorrio et al. 2020), como a los entornos litorales en los que hasta ese momento se habían concentrado las ocupaciones de raigambre fenicio occidental (Rouillard et al. 2007; González Prats 2011; Ros 2017). Ligados o no a un posible descenso demográfico, tales cambios transformaron los paisajes y marcos relacionales de las comunidades de la región, además de alterar los modelos sociopolíticos, económicos y culturales desarrollados desde el s. VIII a.C. (fig. 1).

A nivel territorial, la principal consecuencia de esta coyuntura fue la contracción o directamente el abandono de una parte de los asentamientos de las cuencas de los ríos Segura y Vinalopó. Esta situación ha servido como argumento para vincular estos procesos con la identificada crisis del s. VI a.C. que afecta directamente al mundo fenicio oriental (Elayi 2013: 214-215), y cuyas consecuencias se han traspolado a las colonias fenicias ibéricas (Frankenstein 1997: 211; Aubet 2009: 344 y ss.). Sin embargo, el problema de esta posición es que, más allá de infravalorar la propia autonomía de las colonias occidentales y el carácter de sus relaciones con las economías y sociedades locales (Ruiz y Vallejo 2002: 206), también condiciona el análisis de los grupos autóctonos del Hierro Antiguo bajo una determinada magnificación de los hábitats fenicios y las transformaciones que en ellos se sucedieron (Martín Ruiz 2007: 154).

De esta manera, sin dejar de considerar los importantes efectos que la reestructuración de los entornos coloniales implicó entre las comunidades autóctonas del SE, es necesario adoptar un enfoque consciente de la agencia de estos grupos (Van Dommelen 1998; Vives-Ferrándiz 2005) mediante el que poder identificar sus propios mecanismos y dinámicas internas. Una perspectiva que, dentro de una coyuntura de transición, se vuelve aún más necesaria ya que en la última fase del Hierro Antiguo se encuentra la emergencia del período Ibérico. De ahí la importancia que cobra la revisión de asentamientos con niveles de estas cronologías para realizar aproximaciones menos condicionadas, siendo estas especialmente significativas cuando se trata de asentamientos monofásicos adscritos a esta etapa como parece que es el caso de Los Casarejos (Lorca, R. Murcia).

En el año 2009, durante la construcción de la zanja para un gaseoducto en el paraje conocido como Los Casarejos, se identificaron una serie de niveles arqueológicos que llevaron a la ejecución de una intervención arqueológica al S de la línea practicada. En la memoria redactada y su posterior publicación se planteaba que este yacimiento se adscribía al Bronce Final y perduraba durante la I Edad del Hierro y época ibérica (Mancha 2010). Sin embargo, la revisión de esta intervención ha arrojado unos resultados muy distintos de los hasta ahora presentados, pudiendo adscribir esta ocupación a un momento constreñido al final del Hierro Antiguo y el inicio del Ibérico Antiguo. El objetivo de este trabajo es recuperar este yacimiento para la arqueología del SE presentando los datos obtenidos a partir del análisis acometido de su paisaje, secuencia y repertorio vascular.

\section{LA SEGUNDA MITAD DEL S. VI A.C. EN EL SE IBÉRICO: UNA NUEVA ETAPA DE CAMBIO Y CONTINUIDAD}

A partir del año 550 a.C. se suceden en el SE de la península Ibérica una serie de episodios que marcan el comienzo de una coyuntura de profundos cambios. El nuevo refuerzo de la muralla de Fonteta (Rouillard et al. 2007: 133) se enmarca en un período de conflictividad creciente que se traduce en el horizonte autóctono en el posible asalto y abandono de Peña Negra (Lorrio et al. 2020: 519), así como en una primera destrucción de El Macalón (Chapa et al. 2019: 386). La aparición de puntas de doble filo y arpón lateral en estos yacimientos (Lorrio et al. 2016), la ocultación del tesorillo de Peña Negra (González Prats 1983) y la destrucción intencionada de las esculturas de El Macalón (Cutillas y Navarro 2018: 259), son síntomas evidentes de la magnitud de estas tensiones. No obstante, no todos los episodios de abandono que tuvieron lugar se dieron a raíz de eventos traumáticos y/o violentos, sino que los procesos de reorganización interna también jugaron un papel clave en esta transición.

Este es el caso del abandono de los asentamientos fortificados de Los Almadenes, en la cuenca del río Mundo (Cañavate et al. 2017; Sala et al. 2020); el Cabezo de la Fuente del Murtal, entendido como una parte más del 
Fig. 1: Localización del yacimiento arqueológico de Los Casarejos en el contexto de los asentamientos fenicios y autóctonos del SE ibérico durante el Hierro Antiguo (Elaboración propia. MDT-Instituto Geográfico Nacional).

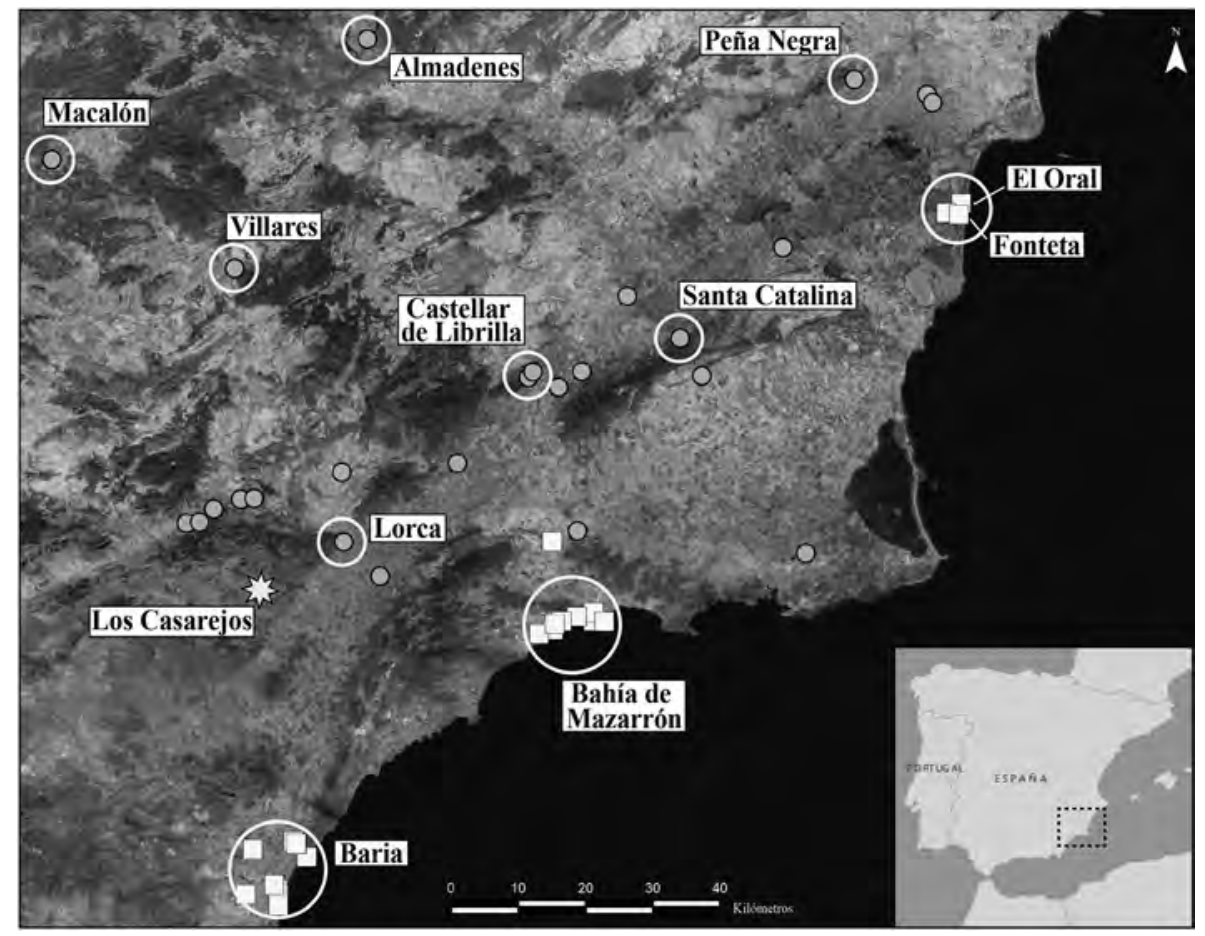

Castellar de Librilla (Cutillas y Ros 2020: 90); o, aún con unos resultados preliminares, posiblemente el Castellar de Villena (Esquembre y Ortega 2017). Misma tendencia se aprecia en el caso de los establecimientos en llano, donde las inestabilidades del sistema provocaron que la mayor parte de estos núcleos no se prolongasen más allá de mediados del s. VI a.C. Los datos procedentes del Campo de Elche, que agrupa los asentamientos de Hacienda Botella, Casa de Secà, Finca del Tío Bou o Galanet (Soriano et al. 2012), o del hinterland de Lorca, con la Torre de Sancho Manuel (Cutillas 2019) y la cuenca del río Corneros (Sánchez González et al. 2010), son muy significativos en tanto reflejan no solo la caída de posiciones concretas, sino el desajuste de redes poblacionales articuladas destinadas a la explotación de un determinado territorio.

La situación en estos escenarios litorales y prelitorales apuntaría a una caída drástica de los sistemas establecidos desde el Bronce Final reciente. Sin embargo, es justamente en este punto donde es necesario ampliar el enfoque para analizar qué está sucediendo en otros de los principales escenarios de la región y cómo estas comunidades, tanto de raigambre local como colonial, se sobreponen a las nuevas dinámicas que tienen lugar durante la transición entre los ss. VI y V a.C.
En la desembocadura del río Segura, el abandono que se detecta en Fonteta durante el último cuarto del s. VI a.C. (Rouillard et al. 2007: 149) es sincrónico a la creación de El Oral, un asentamiento de nueva planta situado en una loma amesetada a dos kilómetros al N (Abad y Sala $1993 ; 2001)$. Su modelo urbanístico complejo y la construcción de su muralla en un momento previo al resto de construcciones del núcleo, denota el carácter planificado de este asentamiento y sirve como argumento para plantear un probable traspaso de población procedente de Fonteta (Sala 2010: 944). Precisamente estos movimientos coinciden con la continuidad de las estructuras de Baria donde, a pesar de entrar en un nuevo período denominado como Fase II o Fenicia Urbana Plena (López Castro et al. 2011: 63), las estructuras en uso durante el s. VI a.C. permanecieron a lo largo de la primera mitad del s. V a.C. (López Castro et al. 2010: 116). Una continuidad que no solo se ha planteado para la colonia, sino también para una parte de las unidades de su hinterland -Hoya de Taray, Garrucha, Salar de la Porrera o Cabecico Parra- que mantuvieron su actividad durante este período (López Castro et al. 2010). Más compleja parece la situación de la Bahía de Mazarrón, a medio camino entre la depresión de Vera y la desembocadura del Segura, debido a la ausencia hasta la fecha de niveles identificados 
adscritos a esta cronología. Pese a ello, la continuidad de este entorno parece demostrada como revelan los hallazgos de materiales tardoarcaicos en Punta de los Gavilanes (Ros y Cutillas 2020) y, más al interior, en El Canal (Correa 2010).

En vista de los datos actuales, estos procesos poblacionales distan de significarse como eventos de abandono o de destrucción de los asentamientos de raigambre colonial; incluso, retratan la agencia de estas comunidades por permanecer en unos entornos ocupados desde el s. VIII a.C. No obstante, esta continuidad también se produce, por un lado, por la emergencia de una nueva dinámica comercial que recupera los territorios del SE ibérico bajo una clara iniciativa de la órbita económica del Círculo del Estrecho en el que los envases anfóricos de la serie T-11 juegan un papel destacado (Abad y Sala 2001; Ros y Cutillas 2020: 794); y, por otro, por la probable pero todavía mal conocida presencia púnica arcaica cuyo reflejo se consolida durante el s. V a.C. y que cristaliza en determinadas manifestaciones arquitectónicas y funerarias como el recinto de culto con emblema en forma de lingote chipriota de El Oral (Sala 2010: 943), los hipogeos de Baria/Villaricos (Astruc 1951; Rodero et al. 1996) o, en el prelitoral, los templos de Lorca equipados con altares en forma de piel de toro (Cárceles et al. 2011; 2015).

En este sentido, la reconfiguración de territorios y asentamientos no se restringió únicamente a los núcleos del litoral. Entre las sociedades autóctonas también se produjeron intensos procesos de reorganización poblacional y remodelaciones urbanísticas que afectaron principalmente a los asentamientos en altura. En el Castellar de Librilla se han podido documentar diversos movimientos internos que llevaron al abandono de los sectores elevados para concentrar su tejido urbano en las zonas medias y bajas del asentamiento (Ros 1989; Cutillas y Ros 2020); mientras que en Santa Catalina del Monte se constataron una serie de niveles adscritos al final del s. VI y la primera mitad del s. V a.C. (Ros 1986-1987: 81) que permiten plantear la continuidad del asentamiento entre ambas fases de plenitud. Más difícil es apuntar qué sucede en Lorca, donde apenas contamos con datos de la fase preibérica -reducidos al contexto productivo de La Alberca (Martínez 2006)-, pero que aparece en el s. V a.C. como un oppidum estructurado cuya entidad lo convirtió en uno de los centros más importantes del SE (López Mondéjar 2012; Cárceles et al. 2015).
Otra reorganización a nivel urbanístico reseñable es la que se ha planteado en Los Saladares, concretamente a partir de la segunda mitad del s. VI a.C. cuando se produce la remodelación de la construcción IV y la edificación poco después de la construcción VI (Arteaga y Serna 1975: 33). La continuidad de este asentamiento, ocupado desde el Bronce Final reciente, se completa con la pervivencia del Cabezo de la Rueda, localizado en la confluencia de los ríos Guadalentín y Segura (García Cano e Iniesta 1987), con una secuencia que arranca probablemente en la primera mitad del s. VI a.C. y que mantiene su ocupación durante este período de transición. En ambos casos se trata de un tipo de asentamiento intermedio entre las unidades productivas tipo granja y los asentamientos principales en altura que probablemente pudo soportar mejor las fluctuaciones del sistema.

Por tanto, el análisis de las dinámicas territoriales y poblacionales del SE ibérico revela como las comunidades que habitaron esta región fueron capaces de sobreponerse a la reconfiguración del horizonte colonial mediante la reestructuración de sus núcleos y la reordenación de sus territorios. No obstante, la implementación de estrategias novedosas no solo se constriñó a procesos de carácter intraurbano o de micromovilidad (Cutillas y Ros 2020), sino que también determinados grupos apostaron por traslados poblacionales y la consiguiente creación de núcleos de nueva planta. A pesar de los escasos datos con los que contamos, es en este marco de movimientos donde consideramos que debe contextualizarse la creación de Los Casarejos, lejos de las principales rutas de comunicación de la región, pero cuyo registro material apunta hacia una plena inserción en los circuitos comerciales regionales y suprarregionales.

\section{EL YACIMIENTO ARQUEOLÓGICO DE LOS CASAREJOS}

\section{CONTEXTO PAISAJÍSTICO Y TERRITORIAL}

El asentamiento de Los Casarejos se localiza en el conjunto de estribaciones de pequeña y mediana altura dispuesto al S de la sierra de la Torrecilla y al O de la Sierra de Cimbre. El encadenamiento de estas alturas, la aridez de su paisaje debido a los afloramientos de esquistos (fig. 2, A), la falta de áreas de cultivo y la ausencia de corredores de comunicación natural han condicionado la escasa densidad de poblamiento en la zona. A ello se suma un 


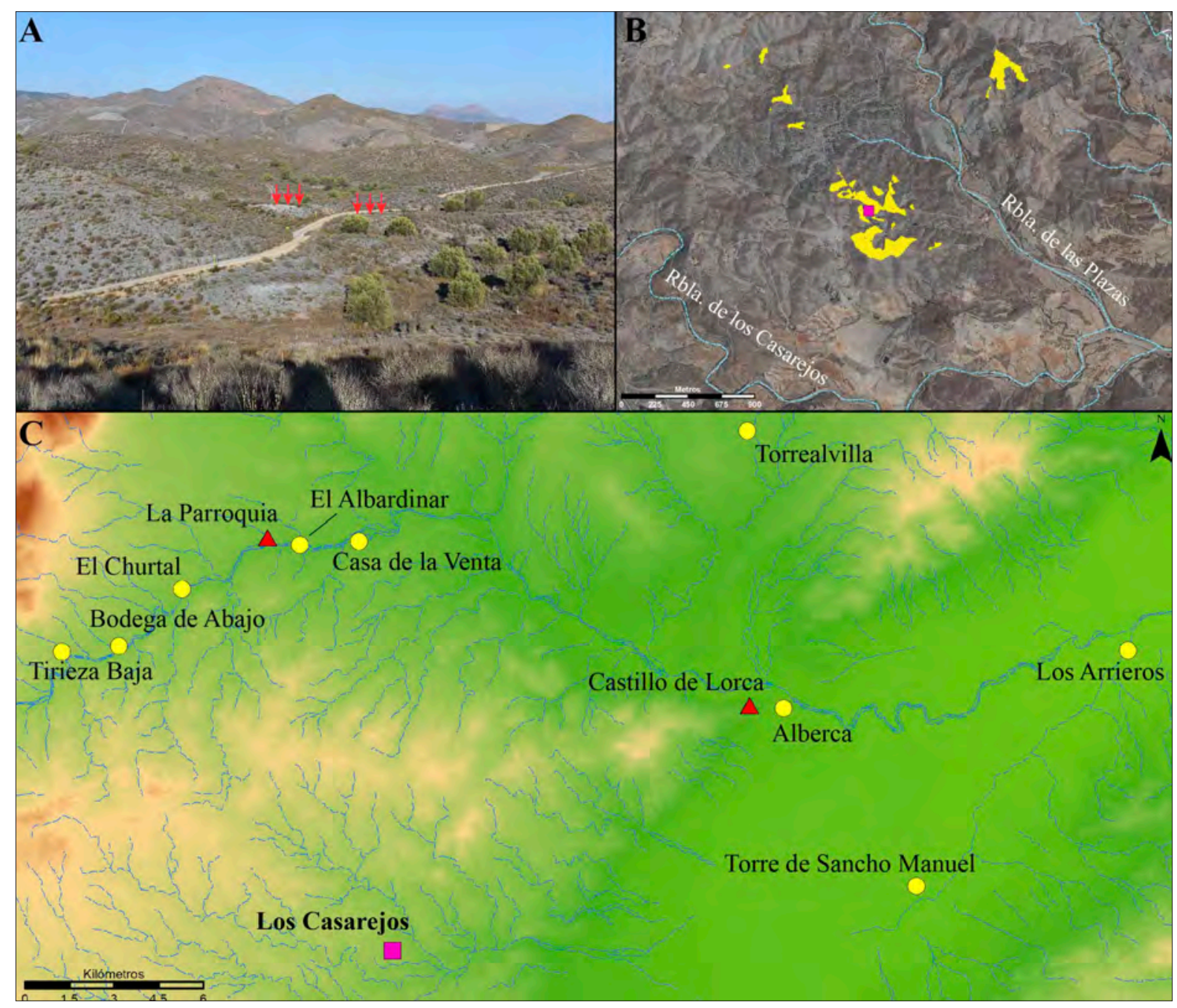

Fig. 2: Entorno en el que se ubica el yacimiento de Los Casarejos (A), análisis de visibilidad desde el asentamiento (B) y distribución de los núcleos identificados en el hinterland de Lorca (C) adscritos al Hierro Antiguo (círculos) o al Ibérico Antiguo (triángulos) (Imagen del autor. Cartografía propia a partir del MDT-IGN).

marco ambiental que tiende hacia una creciente intensificación de la aridez y en la que durante el I milenio a.C. tuvo lugar un importante retroceso de las formaciones boscosas, el establecimiento permanente del matorral mediterráneo y un fuerte aumento de taxones termófilos (García Martínez y Ros 2010: 554-555). Únicamente la existencia de algunas ramblas mitigaría esta situación, como sucede con las ramblas de Las Plazas y Los Casarejos, cercanas al asentamiento aquí tratado y cuyas cuencas transitan hasta desembocar en el valle del Guadalentín.

Sin embargo, el núcleo de Los Casarejos no se encuentra inmediato a ninguno de los cauces anteriores, sino llamativamente alejado de los mismos, concretamente a una distancia de $800 \mathrm{~m}$ de la primera y $1,5 \mathrm{~km}$ de la rambla homónima. Esta separación implica un aislamiento significativo respecto a su entorno inmediato, a lo que se suma su emplazamiento en una posición baja que le reporta un radio de visibilidad realmente reducido (fig. 2, B). Desde la posición en la que se ubicó el asentamiento quedan fuera de su horizonte visual tanto las ramblas citadas, como gran parte de los pasos naturales de la zona.

Las características de la posición de Los Casarejos responden a las propias de un núcleo ubicado en llano entre cuyas atribuciones no se encontraba el control de su territorio (fig. 2, B). De ahí que la elección de este lugar tuvo que ser premeditada ya que las estribaciones próximas 
al asentamiento -tanto la elevación contigua en su lado occidental, como especialmente la inmediata colina del Castellar por su parte meridional- cuentan con cuencas visuales amplias y se constituyen como puntos de control más ventajosos. Sin embargo, a pesar del grado de alteración antrópica que han sufrido en particular las cimas del Castellar, no se han detectado evidencias arqueológicas en sus cimas y laderas a partir de las que inferir la existencia de otras ocupaciones en el entorno. Una condición importante ya que permite descartar por el momento que Los Casarejos pudiera formar parte de un núcleo de mayor entidad que se localizase en sus inmediaciones.

De esta manera, el emplazamiento elegido para la creación de este asentamiento se presenta como uno de los principales interrogantes que aparecen a la hora de abordar la propia idiosincrasia de Los Casarejos. El análisis de las dinámicas poblacionales de la franja prelitoral del SE en general (González Prats 1983; Ros 1989; García Borja et al. 2007; López Castro et al. 2010; Soriano et al. 2012; Lorrio et al. 2020), y de la zona de Lorca en particular (López Mondéjar 2015; Cutillas 2016), revelan que los asentamientos del Hierro Antiguo se posicionaban conectados a cauces fluviales y rutas de paso principales. Además del propio núcleo urbano de Lorca, ubicado junto al río Guadalentín, los asentamientos rurales que posiblemente formaron parte de su hinterland (fig. 2, C) siguieron estos mismos parámetros: en la cuenca del río Corneros, que sirve de unión con la zona de Vélez Blanco, se sitúan Bodega de Abajo I, El Albardinar I, El Churtal, Casa de la Venta I y Tirieza Baja (Sánchez González et al. 2010); en la rambla de Torrealvilla, a medio camino entre Lorca y sierra Espuña, se encuentra el yacimiento del mismo nombre donde, entre otros materiales, se localizó una oil bottle similar a las identificadas en Fonteta (González Prats 2011: 423); y, en tierras óptimas para el cultivo junto a la rambla de la Viznaga, uno de los principales cauces del valle que desemboca en el Guadalentín, los asentamientos de La Torre de Sancho Manuel (Cutillas 2019) y Los Arrieros.

La creación de Los Casarejos rompe con el patrón hasta entonces establecido en un momento, además, de profunda reestructuración del hinterland de Lorca donde parece que todos los asentamientos rurales anteriormente citados desaparecen. A pesar de contar con datos exiguos sobre esta transición, sí que pueden atisbarse ciertos movimientos poblacionales como el que se produce en el valle del río Corneros, donde se dio una reestructuración de las comunidades allí asentadas hacia el núcleo de La Parroquia, en el que se han documentado ánforas del tipo T-11.2.1.3 (Sánchez González et al. 2010: 1155) que remiten a este horizonte transitorio y rompe la idea de vacío poblacional que se había expuesto sobre esta vía (López Mondéjar 2012: 150). Concretamente a uno de estos movimientos que se dan durante la segunda mitad del s. VI a.C. tuvo que deberse la creación de Los Casarejos, si bien es cierto que la elección de su emplazamiento implicase un aislamiento significativo respecto a los principales ejes de comunicación y tránsito del SE.

\section{ESTRUCTURAS, ASENTAMIENTO Y SECUENCIA CRONOESTRATIGRÁFICA}

Según los resultados recogidos en la memoria de excavación de Los Casarejos y su posterior publicación (Mancha y León 2009; Mancha 2010), en las dos cuadrículas planteadas al S de la zanja para la tubería del gas se detectaron hasta tres estructuras negativas consideradas como posibles fosas o basureros. No obstante, la interpretación de estos contextos, junto a los datos presentados y la descripción de los mismos, mostraban una serie de problemas e interrogantes que han acabado por condicionar la propia comprensión de este yacimiento. De ahí la necesidad de revisar esta intervención y la configuración de su registro arqueológico para poder contextualizar tanto los materiales aparecidos, como replantear el significado de estas supuestas estructuras y su vinculación con el asentamiento al que tuvieron que corresponder.

Centrándonos en la cuadrícula de dimensiones mayores, la $\mathrm{C} 1$, el primer aspecto que destaca de esta área de intervención es la identificación de una fosa denominada como Estructura 1 cuya extensión coincide con los límites de la cuadrícula: $13 \mathrm{~m}$ de longitud, más de $3 \mathrm{~m}$ de anchura y 1,30 $\mathrm{m}$ de profundidad aproximada (Mancha 2010: 45). Sin embargo, este último dato difiere de lo descrito para el nivel arqueológico -UE2- que según lo publicado también se encuentra extendido por toda la superficie excavada, pero cuya potencia va modificándose como se refleja en el perfil $\mathrm{N}$ producido por las obras de apertura de la zanja (fig. 3, A). En sentido E-O, la medida inicial de la capa arqueológica documentada apenas alcanza los $25 \mathrm{~cm}$ de potencia, mientras que en su parte central aumenta hasta los $90 \mathrm{~cm}$ y vuelve a disminuir en la zona más oriental hasta los $60 \mathrm{~cm}$ (Mancha y León 2009: 28). Esta disposición se explica por el buzamiento 

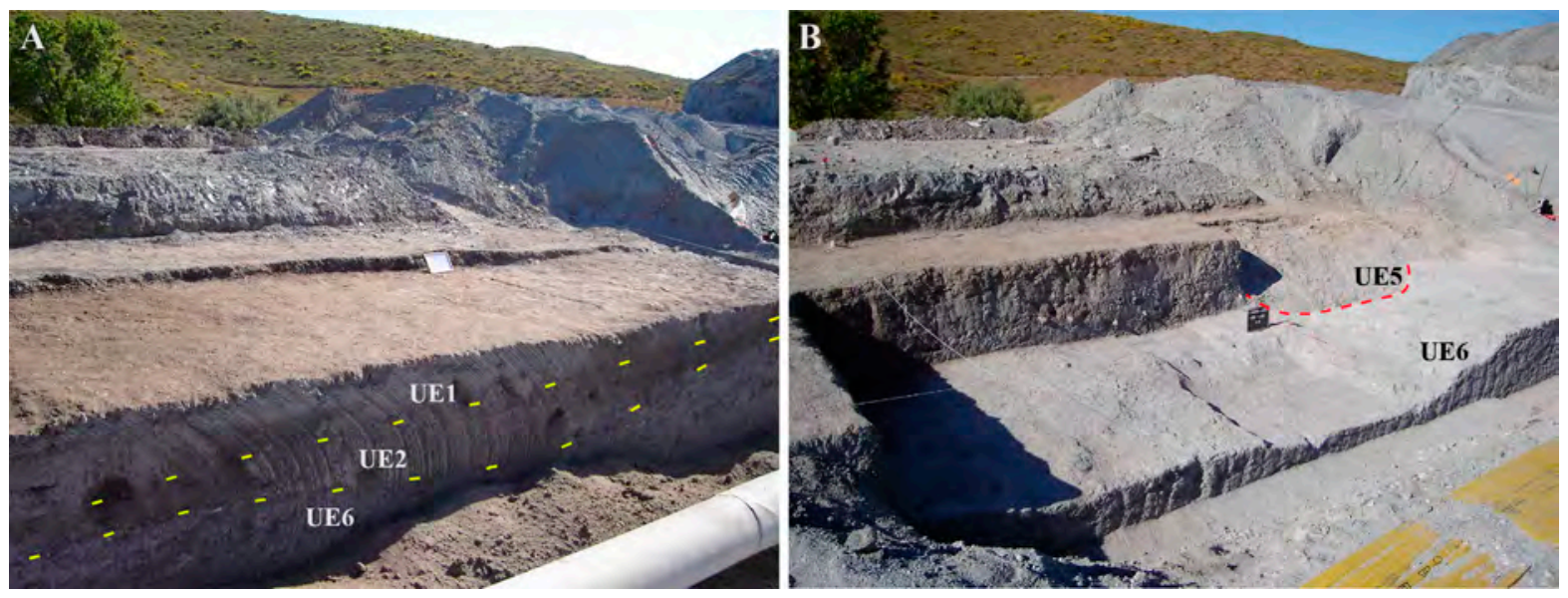

Fig. 3: Vista general de la intervención arqueológica practicada en Los Casarejos antes del inicio de la excavación (A) y una vez finalizada (B) (imágenes extraídas de Mancha y León 2009).

que presenta la capa geológica -compuesta por pizarras y vetas de cuarzo- debido a la existencia de una serie de diversos escalones naturales sobre los que se asienta el nivel arqueológico UE2.

Precisamente es en la interpretación de la relación entre ambas unidades cuando, bajo nuestro punto de vista, aparece uno de los principales problemas de esta intervención. A pesar de valorar el carácter natural de estos desniveles del terreno, sus excavadoras consideraron la zona de contacto entre la capa arqueológica y el buzamiento irregular del nivel geológico como las paredes de tendencia irregular de una posible fosa o estructura (Mancha 2010: 45). Esta identificación, ya de por sí arriesgada en base a la información arqueológica disponible, tampoco se reconocía en el resto de la supuesta estructura como se desprende de la descripción del extremo opuesto de la Cuadrícula 1: el contorno de la estructura negativa se difumina no pudiendo conocer el límite de la misma con claridad (Mancha y León 2009: 25). A esta indefinición se debe añadir la práctica ausencia de materiales arqueológicos en el sector más oriental de la cuadrícula (Mancha 2010: 46), lo que permite cuestionar la existencia de esa estructura.

De esta manera, no hay datos concluyentes que apunten a que el nivel arqueológico o UE2 se encontrase delimitado por una estructura negativa previa, ni tampoco queda contrastada la existencia de esas paredes que, aun siendo de morfología irregular, sirvieran como argumento para justificar la existencia de esta fosa. Los resultados de la excavación únicamente permiten constatar que el nivel arqueológico se adapta a la estructura de la capa geológica, incluyendo el buzamiento natural que ocasiona la mayor profundidad de la UE2 (fig. 3, B), hasta acabar perdiéndose en dirección E conforme se aleja del probable núcleo del asentamiento. Esta lectura se ve contrastada por los resultados obtenidos en la Cuadrícula 2 de la intervención, localizada en una posición más al E y en la que se planteó la existencia de una segunda estructura negativa (Mancha 2010: 46-47) que, a la vista de los datos estratigráficos y los exiguos materiales que aparecieron, debe descartarse. Así, la existencia de estas extensas estructuras negativas de Los Casarejos debe matizarse en gran medida y restringir esta definición a la fosa identificada en la Cuadrícula 1 como UE5. Esta última se interpretó como un basurero que cortaba el nivel arqueológico UE2 (fig. 3, B) y contenía una cantidad significativa de material arqueológico, orgánico y cenizas (Mancha 2010: 45-46); pese a ello, la presencia del mismo tipo de material cerámico que en el resto del yacimiento apunta a que todo el contexto pertenece a un mismo horizonte cronológico.

Ante los datos expuestos, consideramos que la denominada como Estructura 1 responde realmente a un área extensa y abierta para el depósito de desechos de actividades domésticas que se encuentra en uso hasta acabar configurando una zona de basurero en un espacio abierto. En lo relativo al tiempo que este área se mantuvo indirectamente en activo, el análisis de los conjuntos vasculares de los diversos niveles del yacimiento arroja una horquilla temporal muy constreñida a la segunda mitad del s. VI a.C., con probabilidad concentrada en el último tercio del mismo, lo que pondría de manifiesto la reducida 
ocupación de Los Casarejos. No obstante, esta concentración de evidencias arqueológicas no puede entenderse sin plantear la existencia inmediata de ese asentamiento de probable carácter monofásico que justificaría la presencia considerable de material cerámico, restos de fauna, carbones dispersos, fragmentos de metal o pellas de abobe en las UE2 y UE5.
A este respecto se deben tener en cuenta dos consideraciones para plantear tentativamente la localización de las unidades habitacionales que constituyeron el asentamiento de Los Casarejos. Por un lado, la orientación de la capa arqueológica UE2 y la pendiente del nivel geológico sugieren que el área ocupada debería situarse en las posiciones más elevadas que quedan al $\mathrm{O}$ y NO del área

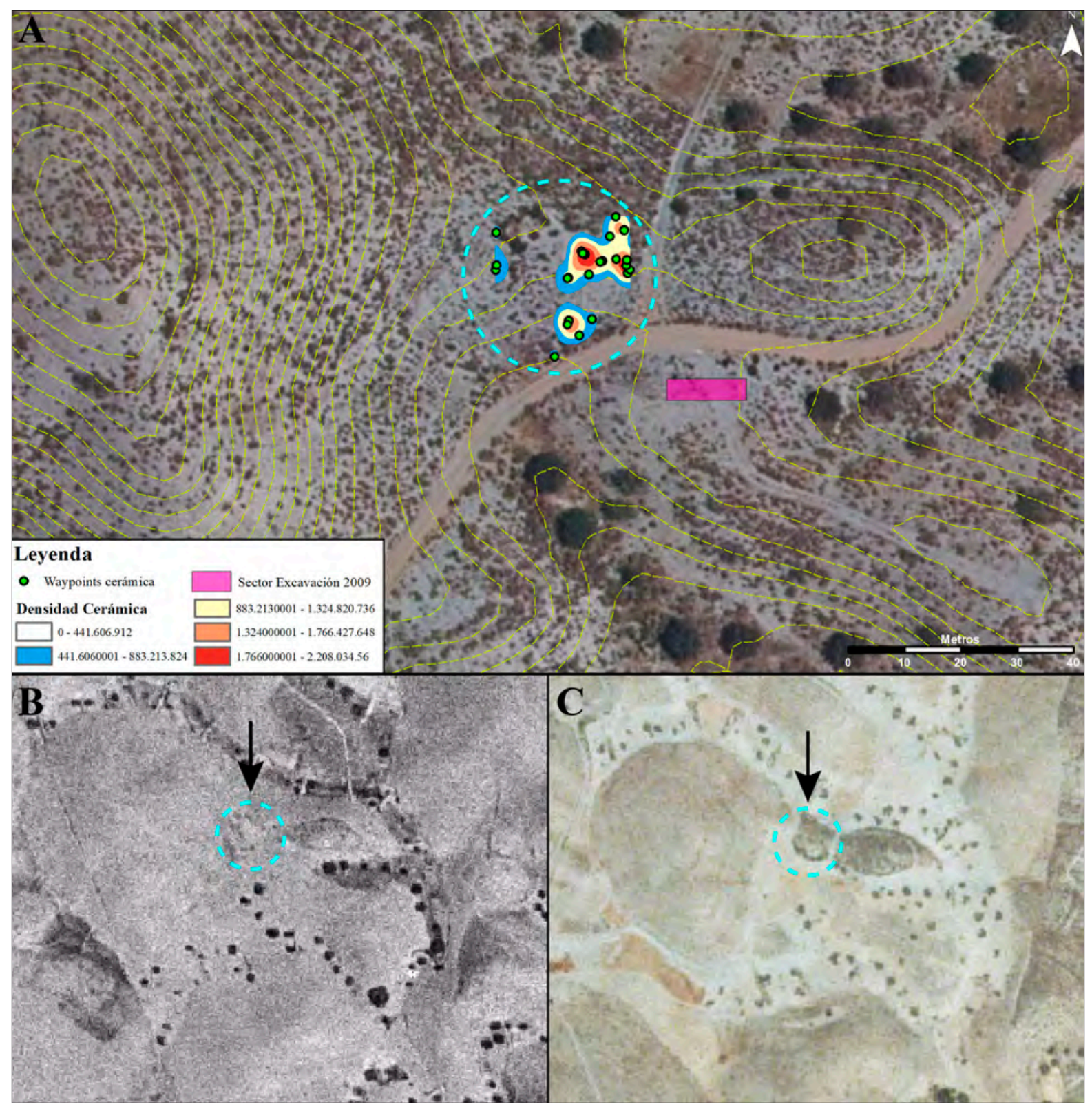

Fig. 4: Distribución microespacial del yacimiento arqueológico de Los Casarejos, incluyendo la localización de la zona intervenida y un análisis de densidad a partir de los restos cerámicos visibles en superficie (A). Fotogramas del vuelo americano de 1956 (B) y quinquenal de 1998-2003 (C) en el que se aprecia con mayor claridad la loma (Imágenes procedentes de la Fototeca del IGN). 
de intervención de 2009, y no hacia el E donde el volumen de evidencias arqueológicas se perdía de forma progresiva. Por otro, durante la inspección del yacimiento se identificó un área próxima con materiales en superficie (fig. 4,A) que se adscriben con claridad al mismo horizonte cronocultural que los materiales identificados en Los Casarejos. Esta concentración se disponía sobre una de las suaves lomas que queda al NO de la excavación y se presenta como un espacio favorable en el que situar un pequeño núcleo y las estructuras habitacionales que lo conformaron por su posición algo más elevada respecto a las zonas bajas de ramblizo como se aprecia en diversas fotografías aéreas históricas (fig. 4, B y C). De ahí que consideremos factible realizar una nueva lectura de Los Casarejos como un asentamiento mayor de lo hasta ahora planteado, con una zona de hábitat situada en la loma citada y una zona más baja al exterior del núcleo como vertedero de desechos de actividades domésticas que coincide con parte del espacio excavado durante la intervención de 2009.

\section{LOS CONTEXTOS CERÁMICOS}

Aunque durante la intervención arqueológica de Los Casarejos se diferenciaron diversas unidades estratigráficas, el examen del repertorio cerámico exhumado apunta a que todos los materiales se adscriben a un horizonte cronológico común. Es por ello que para su análisis y contextualización se ha apostado por un enfoque transversal en el que este registro vascular se analiza desde el punto de vista de la funcionalidad. Esta orientación permite evaluar con mayor precisión los cambios y continuidades que se dan entre las vajillas cerámicas como consecuencia de la evolución de las dinámicas que, a nivel sociocultural y territorial, se dieron en la región durante la segunda mitad del s. VI a.C.

\section{ENVASES Y CONTENEDORES}

La categoría cerámica representada en mayor número es la de los envases de transporte. Partiendo de la premisa de la posible multifuncionalidad de estas cerámicas -concebidas en un primer momento para el transporte de productos y cuya utilidad podía prolongarse en el interior de los espacios domésticos como recipientes contenedor-, son dos los grupos en los que los individuos procedentes de Los Casarejos pueden agruparse: ánforas y jarras o tinajas.
Respecto a las primeras, sobresale la convergencia entre aquellos tipos característicos que se expanden desde la segunda mitad del s. VIII a.C. y la aparición de una serie de nuevas ánforas que marcan el incipiente cambio de período hacia el Ibérico Antiguo. Todas responden a una misma funcionalidad y pueden ser incluidas bajo la categoría de ánforas con cuerpo de saco y hombro carenado. Sin embargo, aunque la identificación de diversos tipos no sea un argumento definitivo para plantear en la mayoría de los casos adscripciones concretas (Ramon 1995: 231; Ros et al. 2016: 229), a partir de la morfología de sus bordes se detecta el cambio incipiente a nivel socioeconómico y material que se está dando en la región.

En este sentido, se han localizado diversas formas que pueden clasificarse dentro del tipo T.10.1.2.1 de Ramon (1995: 463, fig. 109), contando con bordes engrosados de caras rectilíneas y oblicuo exvasados (fig. 5, 1-2; 7-8), en algún caso muy pronunciados (fig. 5, 3) y con una línea de ruptura de perfil al interior (figs. 5, 4-6) que señala tipos ya evolucionados como los identificados en Fonteta VI (González Prats 2011: 357-362). A estas producciones se suman las propias del horizonte autóctono como las ánforas de borde engrosado inclinado al exterior o recto (figs. 5, 9-11) que se enmarcan bajo el tipo VIII.P.5 del Castellar de Librilla (Ros 1989: 286-288), también representado en Los Almadenes (Sala et al. 2020: 845, fig. 5, 40) o dentro del poco preciso tipo B1 de Peña Negra (González Prats 1979: 63). Sin embargo, junto a estas formas tradicionales del Hierro Antiguo, aparece un ánfora con borde corto y perfil triangular engrosado al exterior (fig. 5, 12) con paralelos en el Alt de Benimaquía (Álvarez et al. 2000: 124, fig. 3, 3) y Fonteta $\mathrm{Vb}$ (Rouillard et al. 2007: 314, fig. 250, 4), así como un segundo envase anfórico de borde redondeado con perfil almendrado (fig. 5, 13) que probablemente se sitúa a medio camino entre los tipos de la serie T.10 y las ánforas puramente ibéricas de boca casi plana con bordes almendrados.

Respecto a los envases anfóricos, también se ha de señalar la identificación de dos galbos que cuentan con sendas marcas anepigráficas. La primera se encuentra sobre un fragmento de superficie exterior anaranjada e interior gris clara, que presenta una marca incisa y compleja de la que se han conservado tres trazos rectilíneos, limitados y articulados a partir de un punto (fig. 5, 14) cuya disposición recuerda a alguna de las marcas presentes en las ánforas ibéricas del pecio de Binisafuller (Mata y Soria 


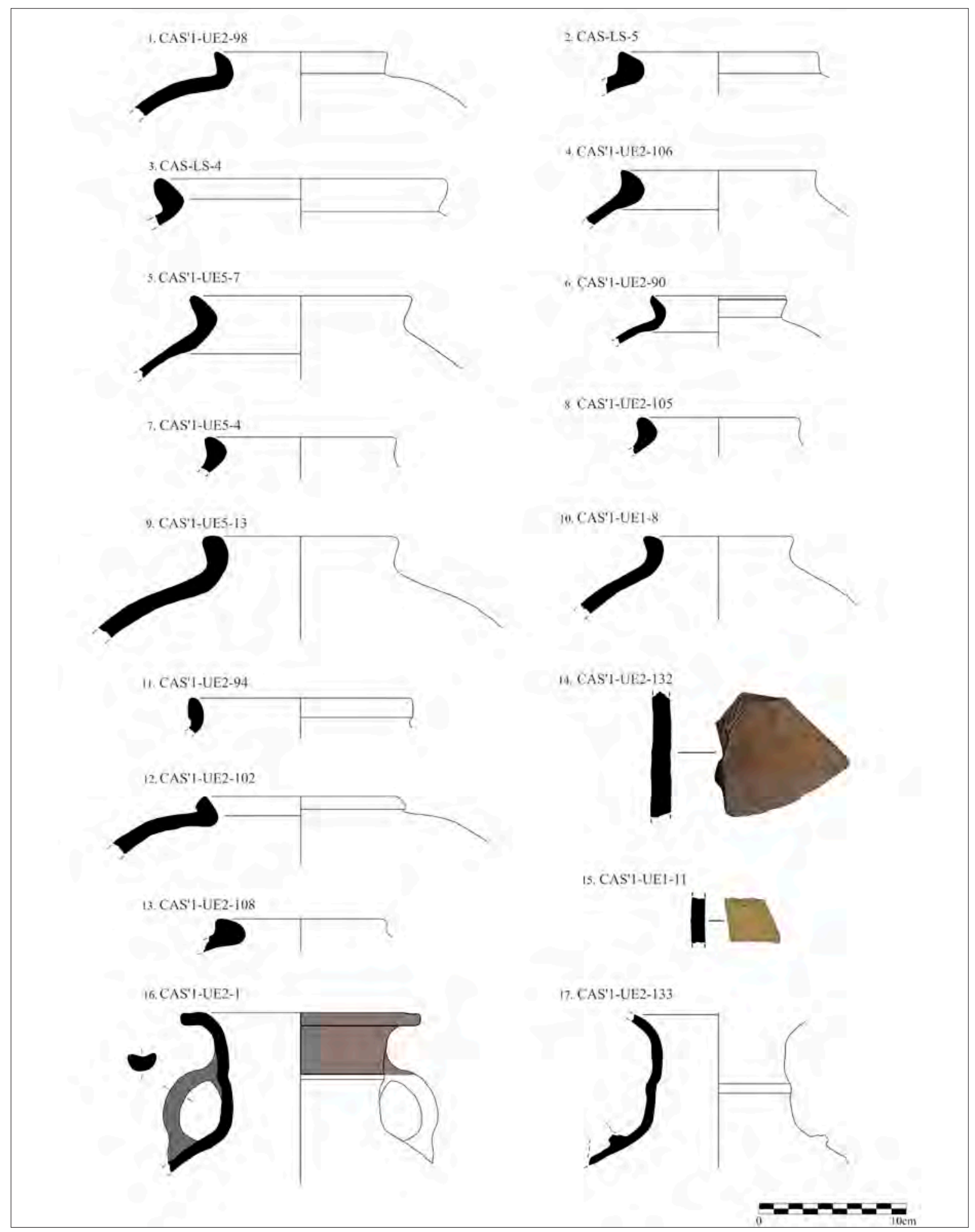

Fig. 5: Repertorio vascular procedente del asentamiento arqueológico de Los Casarejos. Contenedores de transporte. Elaboración del autor. 
1997: 336, fig. 14, Núm. 23.168). En cuanto a la segunda, se trata de una marca impresa de enmarque circular y campo vacío sobre una pared de superficies ocres (fig. 5, 15). Motivos similares se han constatado en el taller alfarero de La Pancha en agrupaciones de tres de estas estampillas (Martín Córdoba et al. 2006: 277, fig. 16) y sus productos alcanzaron la fachada levantina como se constata en la Fase II de Fonteta (Elayi 2011: 277-278). Sin embargo, durante el s. V a.C. también se han detectado agrupaciones de tres enmarques circulares al interior del SE, concretamente en una tinaja de Los Villares y en dos ánforas del Castellón de Hellín, aunque en este último caso los enmarques tienen un tamaño superior y presentan dos pequeñas muescas situadas diametralmente (Mata y Soria 1997: 366, Lám. 4).

En los individuos de Los Casarejos parece posible considerar estas incisiones precocción como marcas de alfar, si bien es difícil plantear por el momento el origen de ambos envases ante los todavía escasos datos con los que contamos sobre este tipo de distintivos alfareros. No obstante, esta cuestión se plantea compleja y va más allá de las meras vajillas cerámicas, pues también se han encontrado marcas circulares en pesas de telar en yacimientos como Camposoto y la Illeta dels Banyets (Zamora 2019: 405-406). Una relación que tentativamente podría poner de manifiesto la conexión entre dos ámbitos peninsulares alejados, pero que se encontraban bien conectadas como se refleja en Los Casarejos a partir de la llegada de otras cerámicas para transporte como las jarras.

El segundo grupo que destaca entre estos recipientes es el formado por aquellos contenedores de capacidad media definidos como jarras. Aunque es posible reconocer diferentes tipos, cumplen una funcionalidad similar y, además, han sido básicos para precisar la cronología de Los Casarejos al tratarse de formas evolucionadas que se sitúan en plena transición hacia el Ibérico Antiguo (Cela 2006). Este es el caso de las jarras tipo Cruz del Negro localizadas en el asentamiento, dos vasos de cuello estrecho con moldura, cuerpo globular y dos asas, pero que presentan una variante en el modo de concebir la forma del borde, con el labio vuelto al exterior como se ha conservado en uno de los individuos (fig. 5, 16-17). Aunque sigan los cánones formales de este tipo de vasos definidos bajo la Forma 35A de Fonteta (González Prats 2014b: 602 y ss.) -al que se podría añadir una tercera jarra con cuello de Los Casarejos (fig. 6, 2), similar a la variante 35B (González Prats 2014b: 636-638)-, se trata de envases que ya no incorporan los acabados tradicionales en engobe rojo o pintura en estilo bícromo. Pueden mantener ciertas partes pintadas, como ocurre con una de las jarras de Los Casarejos que presenta un campo en marrón, pero estos acaban por desaparecer como también le sucede a uno de estos vasos localizado en Fonteta a finales del s. VI a.C. (Rouillard et al. 2007: 304, fig. 240, 14).

Otra de las formas que en este caso destaca por su procedencia es la jarra de espalda carenada sin cuello, borde alto oblicuo y banda pintada en rojo (fig. 6, 1) cuyos paralelos inmediatos se han identificado en El Oral (Abad y Sala 1993: 208, fig. 158) y, probablemente como potenciales focos de origen a falta de análisis arqueométricos, en el taller alfarero de Camposoto bajo el tipo CIIIa1 (Ramon et al. 2007: 77-78 y 243, fig. 151) y Málaga (Arancibia et al. 2021: 272-273, fig. $5,10)$. La aparición de esta jarra permite, por un lado, reconocer la participación de Los Casarejos en circuitos comerciales de largo alcance como los desarrollados por el círculo gadirita en época tardoarcaica (Ros y Cutillas 2020); y, por otro, precisar la cronología este asentamiento a finales del s. VI a.C. considerando estas jarras dentro de las primeras producciones del alfar gadirita. Estas conexiones con el mediodía peninsular también se reflejan en la llegada de otros vasos de origen foráneo como el contenedor CAS'1-UE2-82 (fig. 6, 9), una olla de transporte de borde engrosado vuelto al exterior con paralelos en Cerro del Villar (Aubet et al. 1999: 119, fig. 75, c), y el lebrillo CAS'1UE2-181 (fig. 6, 12) que también cuenta con paralelos en Cerro del Villar (Aubet et al. 1999: 233, 151,f-g) y podría enmarcarse dentro del tipo BIIIb de Camposoto (Ramon et al. 2007: 239-240, figs. 147-148).

Este marco cronológico se ve reforzado por la importancia que cobran en el registro material de Los Casarejos los contenedores de tendencia bicónica con borde exvasado y labio vuelto al exterior recto o de perfil triangular muy estilizado. Estas formas han sido denominadas como jarras (Rouillard et al. 2007), urnas (Abad y Sala 1993: 158) o tinajillas (Grau y Segura 2013: 99), pero, en esencia, representan un mismo tipo cerámico que responde a la evolución de las jarras tipo pithoi (González Prats 1979: 89; Ros 1989: 268 y ss.; Pla 2014) que adelgazan sus perfiles y pierden sus asas hasta constituirse en uno de los tipos principales y más extendidos durante el período ibérico (Mata y Bonet 1992: 149-151). Las primeras apariciones en el SE ibérico de 


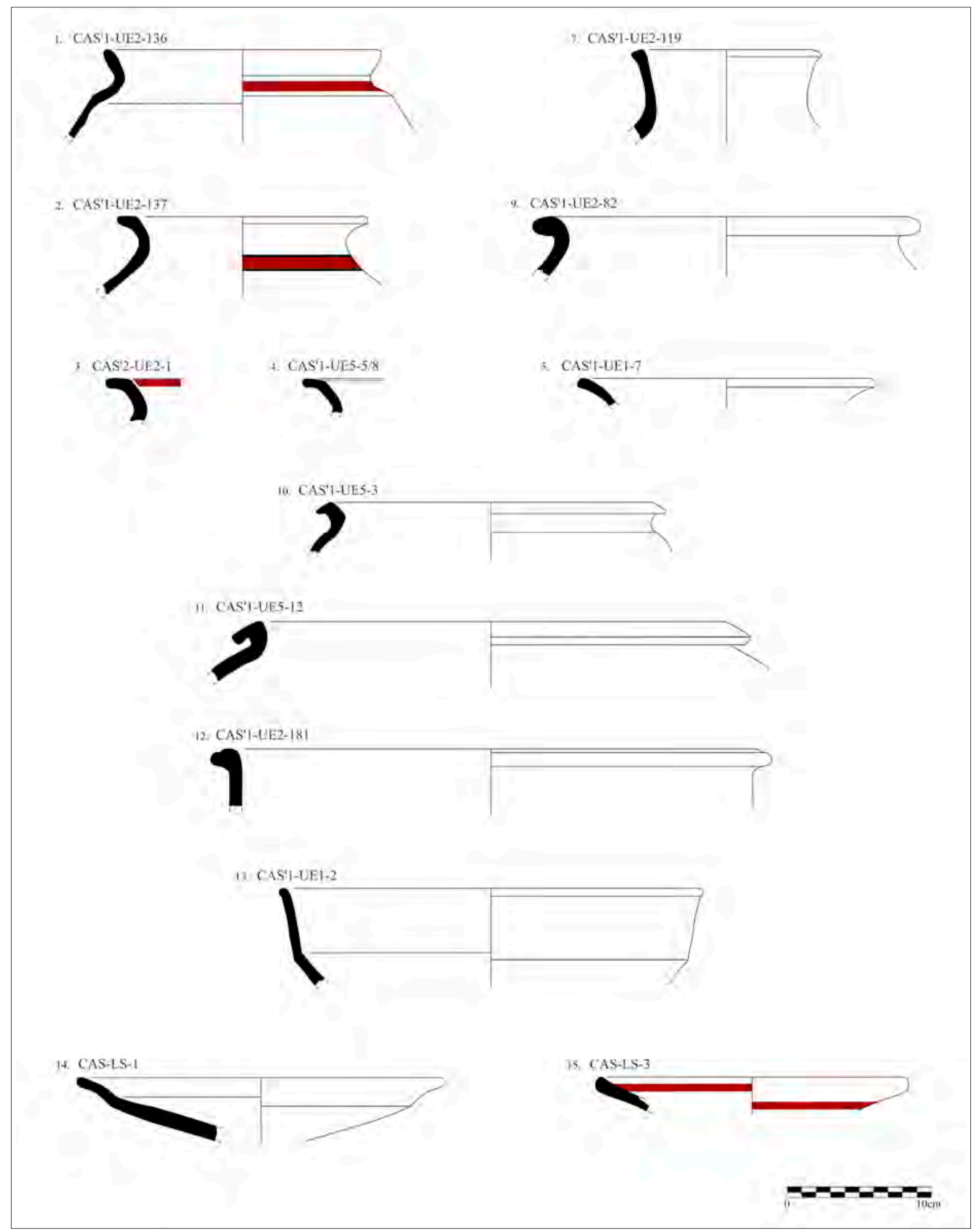

Fig. 6: Repertorio vascular procedente del asentamiento arqueológico de Los Casarejos. Contenedores de transporte y vajilla de mesa. Elaboración del autor. 
este tipo de jarras se aprecian en el segundo cuarto del s. VI a.C. en Fonteta (Rouillard et al. 2007: 269, fig. 208, 5-6), en la Fase I de Baria (López Castro et al. 2011: 61, fig. 26) o en Los Almadenes (Sala et al. 2020: fig. 5, 10). Sin embargo, es a partir de la segunda mitad del s. VI a.C. cuando estas formas comienzan a generalizarse tanto en los asentamientos coloniales, como en determinados núcleos autóctonos como Peña Negra, bajo los tipos 25 y 26 (González Prats 1979: 88); el Castellar de Librilla con el tipo K.7 (Ros 1989: 273274); el Puig d'Alcoi (Grau y Segura 2013: 99); o Los Saladares a partir de su fase IIB (Arteaga y Serna 1975: figs. 29 y 30).

En Los Casarejos no solo se han identificado varias de estas jarras, algunas con decoración pintada a modo de bandas rojizas (fig. 6, 2-4), sino que también aparecen otros contenedores que se significan como elementos reconocibles de la transición hacia los nuevos cánones formales, funcionales y estéticos que se generalizarán durante la Segunda Edad del Hierro. Nos referimos a una tinaja de cuerpo profundo, hombro marcado y perfil abierto mediante labio saliente de sección triangular (fig. 6, 10) y un protolebes de cuerpo globular, borde recto y labio vuelto al exterior muy pendiente (fig. 6 , 11). Individuos similares se encuentran en un número muy elevado en El Oral (Abad y Sala 1993: 210-211) y también se han localizado en los niveles de transición e ibéricos de los cortes C3 y D3 de Santa Catalina del Monte (Ros 1986-1987).

\section{SERVICIOS DE MESA}

El primer aspecto que sobresale de la vajilla de mesa localizada en Los Casarejos es la drástica desaparición de recipientes manufacturados a mano y los cambios que a nivel tipológico y estético se dan entre las producciones a torno. Ambas dinámicas se enmarcan en el período de tránsito que se produce a finales del s. VI e inicios del s. V a.C. y sus repercusiones se repiten con cierta similitud en otros asentamientos de la región como el Castellar de Librilla (Ros 1989: 384) o Los Saladares (Arteaga y Serna 1975: 70-71). El abandono de las formas tradicionales a mano se acompaña del de otras producciones de raigambre colonial como los engobes rojos, desplazando así gran parte de los ajuares propios del Hierro Antiguo para dar paso a un nuevo ajuar cuyo éxito se demuestra en su generalización durante el período ibérico. No obstante, estas modificaciones también provocaron otros cambios significativos a nivel tipológico y estético que permiten retratar la complejidad material de esta fase.

Una de las principales características del repertorio de mesa de Los Casarejos es el predominio de los platos sin labio y de galbo continuo en forma de casquete esférico que acaban en fondo plano con el talón indicado. Aunque se hayan identificado diversas variantes de este tipo en función de la forma del extremo del borde -redondeado (fig. 7, 1-5), almendrado (fig. 7, 6-9) o de tendencia reentrante con bisel interior (fig. 7, 10-12)-, es muy significativa la desaparición total de platos de ala o labio vuelto al exterior, una de las formas más típicas del Hierro Antiguo que fue adaptada y reproducida por los alfares de los asentamientos autóctonos. Únicamente el individuo CAS-LS-1 presenta un borde al exterior con labio redondeado y carena media-alta (fig. 6, 14), una forma muy específica de plato que, además de ser similar a la forma B5a de Peña Negra (González Prats 1979: 82), también se ha identificado entre los materiales inéditos procedentes de la intervención de La Alberca en Lorca (Martínez 2006).

Más allá de la cuestión tipológica, el abandono de esta variante de plato conlleva una serie de cambios significativos en términos de comensalidad y posiblemente dietas que apuntan a ese horizonte de transición entre dos horizontes en el que se sitúa Los Casarejos. Por un lado, la generalización del casquete esférico con bordes rectos podría suponer un mayor protagonismo de alimentos líquidos o semisólidos, mientras que los labios reentrantes favorecerían a un menor derrame de los mismos. Por otro, la pérdida del borde o ala vuelta supuso una alteración significativa en los gestos practicados en torno a la comensalidad que principalmente afectaron al modo de sujeción y el paso del plato de un comensal a otro. De esta manera, se podría plantear tentativamente que entre las consecuencias del desvanecimiento de estos perfiles se encontró un menor dinamismo en los ámbitos de comensalidad colectiva, frente a la pervivencia de aquellos platos que por su propia forma eran más propicios para un consumo de tipo individual.

Estas apreciaciones a partir de un tipo concreto de vajilla, sin embargo, también se pueden extraer del análisis de otros elementos de los servicios de mesa identificados en el asentamiento o, incluso, de las ausencias. Tal es el caso de las fuentes, una de las principales formas de los servicios cerámicos de mesa desde el Bronce Final pleno (González Prats 1990: 266-267; Ros 1990: 354; Lorrio 2008: 222 y ss.; García Borja et al. 2007: 97 y 100; García Borja et al. 2010: 47) y cuyo éxito perdura durante el 


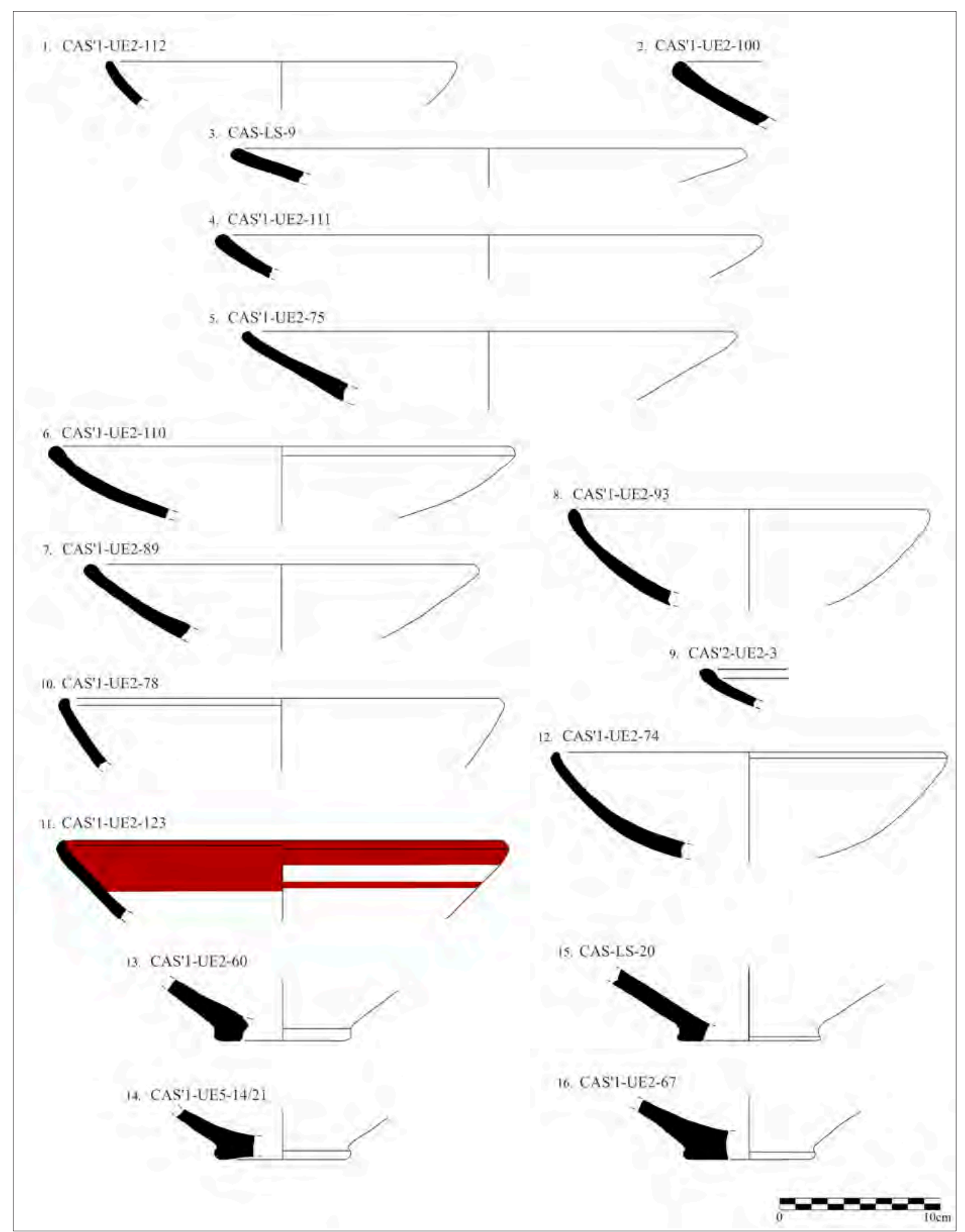

Fig. 7: Repertorio vascular procedente del asentamiento arqueológico de Los Casarejos. Vajilla de mesa. Elaboración del autor. 
Hierro Antiguo (Arteaga y Serna 1975: Láms. 13 y 19; González Prats 1983; Ros 1989: 211 y ss.), que, sin embargo, apenas encontramos representada en Los Casarejos. Sólo el individuo CAS'1-UE1-2 se corresponde con una fuente abierta con borde recto ligeramente exvasado, labio redondeado vuelto al exterior y carena media que conserva un bruñido de buena calidad (fig. 6, 13) con paralelos en la Fase II de La Torre de Sancho Manuel (Cutillas 2019: 23, Lám. 6) y Los Villares del Estrecho de la Encarnación (Ros et al. 2016: 230, fig. 8).

Otro ejemplo claro del mayor protagonismo de las formas cerámicas destinadas al consumo individual, concretamente relacionadas con la bebida, se reconoce en la aparición de dos pequeños cuencos de tipo caliciforme con borde exvasado y carena sin marcar (fig. 8, 3-4). En torno al origen de estos vasos, se ha planteado que se trate de la evolución de los pequeños cuencos de carena media o alta del horizonte Peña Negra I (González Prats 1983: 190; Abad y Sala 1993: 2015). No obstante, en nuestra opinión estos caliciformes estarían más relacionados con aquellos cuencos carenados o tacitas de paredes finas cuyo diámetro es inferior a $10 \mathrm{~cm}$ y que se identifican en el Castellar de Librilla -Tipos D.2 y E.3 (Ros 1989: 234-239)-, Villares (Ros et al. 2016: 230, fig. 8) o la Torre de Sancho Manuel (Cutillas 2019: 18, Lám. 2, 16). En cualquier caso, parece que en la segunda mitad del s. VI a.C. comienzan a aparecer estos caliciformes en el SE ibérico bajo las directrices propias con las que se acabará generalizando en época ibérica. A los dos individuos de Los Casarejos se suma un ejemplar de este tipo de vaso producido en cerámica gris y localizado en Fonteta (Rouillard et al. 2007: 289, fig. 226, 9), mientras que son varios los ejemplares en cerámica gris, pintada y común localizados en El Oral a partir del s. V a.C. (Abad y Sala 1993: 213, 215 y 220).

Pero los caliciformes de Los Casarejos no solo son significativos por la novedad tipológica que suponen, sino que también destacan por encontrarse realizados en atmósferas oxidantes de cocción y contar con superficies anaranjadas alisadas; una apariencia que también se repite en el vaso de perfil en " $\mathrm{S}$ " y carena completamente redondeada (fig. 8, 1). Este cambio de acabados y, por ende, de estéticas aplicadas, debe contextualizarse en ese ambiente de transformación que afecta por entero a las vajillas cerámicas en esta fase. A nivel productivo, durante este último período del s. VI a.C. las cerámicas grises (fig. 6, 13-14 y fig. 7, 5-6 y 8-10) comienzan a verse desplazadas por esos nuevos recipientes con superficies marrones, beige o anaranjadas de cocción oxidante (fig. 7, $1-4,6-7,12)$ y que pueden presentar pintura roja a modo de bandas o campos (figs. 6, 15 y 7,11). Esto implica a su vez un cambio de tendencia en las estrategias productivas de los talleres alfareros y una modificación importante en los gustos y hábitos de consumo de las comunidades del SE ibérico. La estética gris de acabados bruñidos se va a resentir a partir de este período, aunque no llegará a desaparecer durante los siglos siguientes y todavía presenta ciertas producciones innovadoras como sucede con el soporte anular de perfil escalonado CAS'1-UE5-50, una forma evolucionada sin paralelos claros hasta el momento (fig. 8, 2). A pesar de ello, el paso de estas vajillas grises a un segundo plano es ya una realidad como demuestra el repertorio material de Los Casarejos, tanto en el caso de los servicios de mesa, como en gran parte de los contenedores de almacenaje tipo jarras y tinajillas manufacturadas bajo estas nuevas técnicas y acabados.

\section{RECIPIENTES DE COCINA}

El servicio cerámico destinado al procesamiento y preparación de los alimentos de Los Casarejos destaca por estar exclusivamente compuesto por producciones manufacturadas a mano. Esta tendencia productiva difiere de lo hasta ahora expuesto sobre el repertorio vascular del asentamiento, pero es altamente significativo ya que retrata la continuidad de los repertorios de cocina y parte de las dietas asociadas. La forma principal identificada es la olla globular mediana con borde inclinado al interior y labio redondeado que se encuentra puntualmente apuntado (fig. 8, 5-7), así como fondo plano que puede o no contar con talón indicado (fig. 8, 8-15). Aunque es más que probable que no todos los individuos estuvieran destinados a funciones de cocina, sus pastas de factura gruesa y con una cantidad significativa de inclusiones plásticas les prepararía para soportar los continuos choques térmicos resultado de la proximidad al fuego durante el cocinado.

A nivel tipológico, esta clase de olla se encuentra muy extendida por los ambientes domésticos del Bronce Final y el Hierro Antiguo, habiendo sido definida en el SE ibérico, entre otros, bajo los tipos II.F.1 y II.F.4 del Castellar de Librilla (Ros 1989: 242-243), A2 y A3 de Peña Negra (González Prats 1983: 64 y 65), A7 de Mola d'Agres (Peña et al. 1996: 102) e, incluso, en el registro vascular de Fonteta bajo el tipo A2 (Ortiz 2014: 26-28). No obstante, lo que destaca de estos recipientes cuyas formas y estéticas 


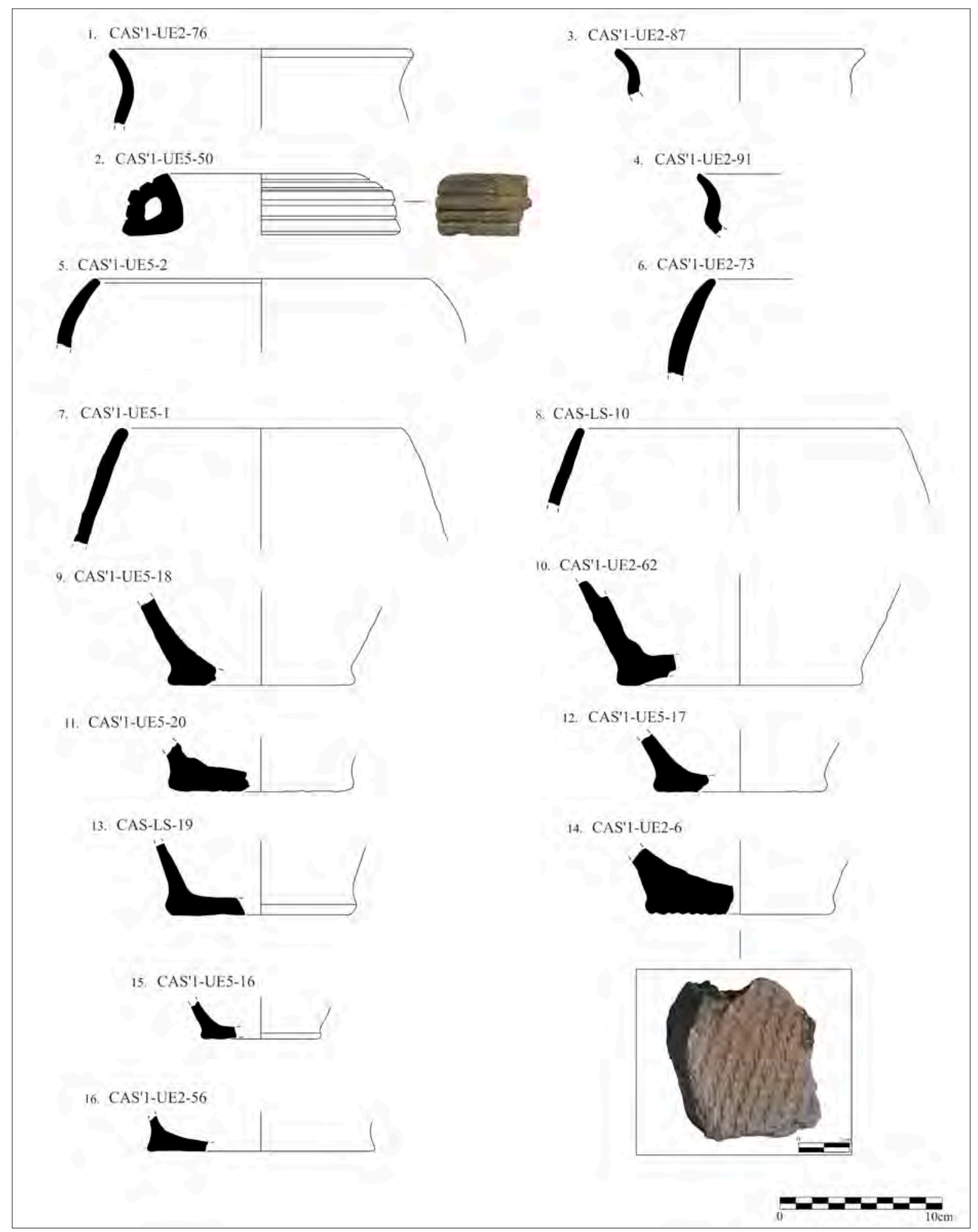

Fig. 8: Repertorio vascular procedente del asentamiento arqueológico de Los Casarejos. Vajilla de mesa y servicios de cocina. Elaboración del autor. 
arraigan en el repertorio vascular argárico es su perduración hasta el final del s. VI a.C., como se ha comprobado en Fonteta (Rouillard et al. 2007: 310-312), y alcanzando las primeras décadas del s. V a.C. en el Puig d'Alcoi (Grau y Segura 2013: 96-97) o el Castellar de Librilla (Ros 1989: 365 y 382). Una realidad que, por el contrario, no se da en el asentamiento de El Oral, donde a inicios del s. V a.C. las ollas de cocina se limitan a producciones exclusivamente a torno (Abad y Sala 1993: 222-223) y que permite retratar el inicio del abandono de las ollas a mano para dar paso a la generalización de las ollas a torno que se encuentran plenamente establecidas en el SE a mediados del s. V a.C.

De esta manera, la ausencia de recipientes de cocina a torno y de otros materiales manufacturados a mano que no sean ollas de cocina -o secundariamente de almacenaje- permite contrastar la cronología planteada para Los Casarejos en el último tercio del s. VI a.C. o inicios del V a.C. La resistencia por mantener los tipos y producciones tradicionales no solo se aprecia a nivel tipológico, sino que las estéticas y pastas elegidas apenas cambian respecto a las de las centurias anteriores; algo que se aprecia con claridad en la impronta de esterilla que presenta el fondo plano CAS'1-UE2-6 (fig. 8, 14) y que responde a un gesto cultural muy marcado del Bronce Final del SE (Papí 1992-94) que se mantiene hasta este período. De ahí que, a pesar de los cambios que se están dando a nivel tecnológico y en términos de consumo de otras vajillas cerámicas, es evidente la agencia de las comunidades autóctonas por mantener sus formas y estrategias tradicionales de cocinar y preparar sus alimentos.

\section{MOVILIDAD POBLACIONAL Y REAJUSTE TERRITORIAL EN EL SE IBÉRICO A PARTIR DEL ASENTAMIENTO MONOFÁSICO DE LOS CASAREJOS}

En un contexto en el que el abandono y los procesos de contracción y reorientación urbana parecen la norma (Ros 1989; Lorrio et al. 2016; Cutillas y Ros 2020; Sala et al. 2020), los datos recuperados de Los Casarejos ponen de manifiesto una realidad novedosa para este horizonte, a la par que complementaria respecto a las dinámicas descritas hasta el momento. Precisamente, uno de los problemas más importantes que aparecen al final del Hierro Antiguo es reconocer hacia dónde se dirigen las comunidades que abandonan parte de los asentamientos de este período. De ahí la oportunidad de contar con un núcleo de nueva planta y adscrito probablemente por entero a esta fase con el que mejorar nuestro conocimiento sobre esta transición, aunque es cierto que este yacimiento no se encontraba exento de problemáticas por su secuencia cronoestratigráfica (Mancha y León 2009; Mancha 2010) y su localización en una zona en principio poco apta para cualquier tipo de poblamiento.

La reinterpretación planteada del registro arqueológico permite descartar esa idea de Los Casarejos como dos fosas basurero, con la excepción de la estructura UE5. Las fosas se entienden como un tipo de unidad negativa que responde a un acto humano intencionado y que, con posterioridad, son rellenadas de forma natural o antrópica. Es cierto que durante el Bronce Final reciente y la transición hacia el Hierro Antiguo se han detectado en diversos puntos de la península Ibérica estructuras excavadas en el sustrato geológico, algunas de dimensiones considerables que se aproximan a las medidas que se atribuyen a Los Casarejos, como Salsa 3 en el Bajo Alentejo (De Deus et al. 2010), Pocito Chicho (Ruiz y López Amador 2001), Villares de Jerez de la Frontera en Cádiz (López Rosendo 2009) o Cortijo Riquelme en la Depresión de Vera (López Castro et al. 2017). Sin embargo, la característica principal de estos contextos -al igual que otros de menores dimensiones y geográficamente más cercanos como es el de Casa de Secà (Soriano et al. 2012)-, es que esos rellenos se realicen sobre una fosa practicada previamente cuyo resultado es la generación de depósitos antrópicos estructurados (Suárez y Márquez 2014; López Castro et al. 2017).

En este sentido, consideramos que los niveles documentados en Los Casarejos no se pueden clasificar dentro de estas fosas-estructuras, sino que responden a la deposición de desechos de actividades domésticas en un área abierta en la que se aprovecha la pendiente que dibuja el propio estrato geológico y que termina por adquirir un cierto carácter estructurado. De ahí que no se encontrasen los límites de ninguna estructura negativa y los materiales arqueológicos disminuyeran hacia su costado oriental. Así, el planteamiento de esta hipótesis y la orientación de los niveles ha sido fundamental para apuntar que lo excavado en 2009 se trata de un contexto ubicado al exterior o en el límite de la zona nuclear del asentamiento, la cual debe emplazarse en la suave loma que todavía hoy se conserva al $\mathrm{N}$ de la zanja practicada y en la que se ha identificado una concentración significativa de material sincrónico en superficie. 
Este tipo de patrón en el que se aprovechan zonas algo sobreelevadas no es extraño entre los asentamientos localizados en zonas rurales, aunque su emplazamiento no perseguía en ningún caso mejorar sus capacidades visuales o defensivas. En el valle del Corneros, los núcleos de Bodega de Abajo, Casa de la Venta I y El Churtal se ubican sobre terrenos de suave pendiente que no destacan sobre su paisaje inmediato (Sánchez González et al. 2010), algo que también sucede en el Cabezo Ventura de Cartagena, donde el núcleo poblacional se restringe al inicio de la falda de la propia elevación (Cutillas 2018: 81). La definición del tipo de asentamiento al que corresponde Los Casarejos era una de las cuestiones que quedaba pendiente, además de ser una información básica para contextualizar el registro arqueológico documentado tanto a nivel cronológico, como vascular y funcional.

El análisis del repertorio vascular exhumado revela que este asentamiento estuvo ocupado apenas unas décadas en un horizonte próximo al último tercio del s. VI a.C., quizás alcanzando los inicios de la centuria siguiente. Por ello el drástico retroceso que sufren las producciones a mano y el incipiente cambio que se produce a nivel tipológico, funcional y estético entre las vajillas de mesa

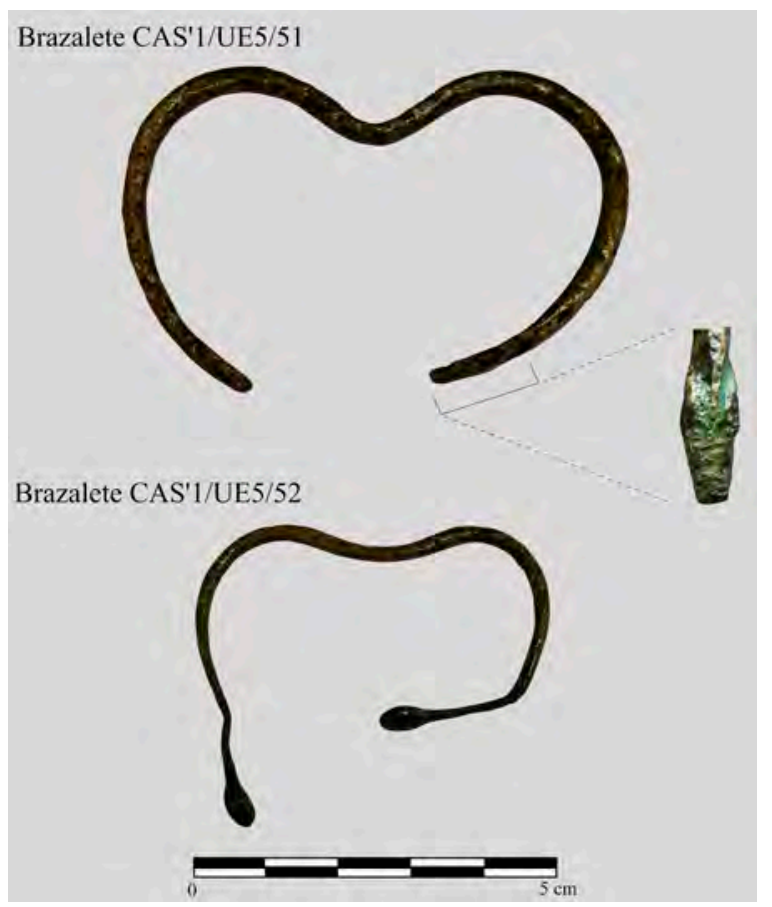

Fig. 9: Brazaletes de bronce identificados en Los Casarejos y detalle de uno de los extremos en forma de cabeza de serpiente (Fotografías del autor). y transporte/almacenaje. El abandono de la cerámica a mano es evidente, ausente entre los registros de mesa y cuya presencia se limita a las ollas de cocina o posible almacenaje. En total, el porcentaje de número de individuos a mano se queda en el 9,8\% del registro total del yacimiento, pero es altamente significativo que precisamente perviva en las vajillas destinadas a la preparación de los alimentos. Esta respuesta cristaliza la agencia y resistencia cultural de las sociedades autóctonas por mantener desde el Bronce Final determinadas tradiciones y costumbres tan ligadas a la identidad como son las relacionadas con la cocina y la alimentación.

En cuanto a las producciones torneadas, estas incrementan su presencia a la vez que basculan hacia nuevos tipos y estéticas cada vez más alejadas de los ajuares tradicionales del Hierro Antiguo. Sobre estos cambios estuvieron que influir ciertas modificaciones alrededor de las prácticas de comensalidad, más relacionadas con la individualidad como suele suceder en período de crisis o transformación social. Esto se tradujo en los servicios de mesa en la desaparición de las fuentes y platos de ala vuelta, dando paso al éxito de los platos de casquete esféricos y los incipientes caliciformes. A la iberización de las vajillas (Cela 2006) también contribuyó la desaparición de los acabados en engobe rojo y el menor protagonismo de la cerámica gris, en gran parte sustituida por pastas anaranjadas o marrones de cocción oxidante que pueden incorporar motivos simples pintados, principalmente bandas y líneas en este período de transición. Todo ello sin dejar de lado las innovaciones que tienen lugar entre los envases de transporte y almacenaje, con la aparición de ánforas y contenedores propiamente ibéricos, la llegada de formas novedosas como las jarras Cruz del Negro evolucionadas o la irrupción de las jarras tipo tinajilla.

Esta situación que se percibe en Los Casarejos también se ha detectado en otros asentamientos de la región, como en el Castellar de Librilla, donde en el último cuarto del s. VI a.C. hay una cierta resistencia de los tipos tradicionales a mano y la cerámica gris bruñida (Ros 1989: 365-366), aunque acaban disminuyendo de forma significativa en el segundo cuarto del s. V a.C. y la cerámica a torno sin tratamiento dobla su presencia (Ros 1989: 292). Este proceso también se aprecia en Los Saladares, concretamente en sus Fases IIA, IIB y IIC, donde la cerámica a mano acaba desapareciendo y se incrementan las cerámicas a torno significativamente distintas a las del período anterior, con pastas marrones claras sin 
tratamiento o decoradas con franjas y motivos geométricos que apuntan a la nueva estética ibérica (Arteaga y Serna 1975: 70-71). Tampoco el asentamiento colonial de Fonteta se queda fuera de esta dinámica, ya que en la segunda mitad del s. VI a.C. se produce una disminución importante de las cerámicas de engobe rojo que se contrarresta con un incremento de la cerámica gris, aunque lo que sobresale es la aparición e incremento de la cerámica definida como ibérica pintada y de pasta clara entre los platos y las cerámicas de almacenaje (Rouillard et al.2007).

Sin embargo, a pesar de estos cambios que podrían apuntar a una regionalización de los circuitos productivos y comerciales, la identificación en Los Casarejos de importaciones del Círculo del Estrecho y la zona malagueña apunta a las conexiones que mantuvo este asentamiento a pesar de su particular emplazamiento, así como una creciente presencia tardoarcaica que se confirmará poco después con la presencia de ánforas T.11.2.1.3 en la región (Abad y Sala 1993; Ros y Cutillas 2020). Esto nos debe llevar a cuestionarnos sobre el tipo de comunidad que se instaló en Los Casarejos, pues, aunque las características del yacimiento apunten hacia un asentamiento de tipo rural, su ajuar cerámico podría corresponderse con el identificado en cualquier yacimiento principal en altura de este período. Esta hipótesis se ve además reforzada por el hallazgo de dos brazaletes de bronce que se constituyen en elementos de prestigio de notable valor destinados además a círculos de consumo restringidos (Jiménez 2002).

Este tipo de brazaletes de forma acorazonada y extremos ensanchados (fig. 9) se encuentra bien representado en otros enclaves fenicios arcaicos como Morro de Mezquitilla (Mansel 2000: 1612, fig. 9) o la propia Fonteta, donde se han localizado un total de 20 ejemplares (González Prats 2014a: 257-259), así como en yacimientos autóctonos con marcadas influencias coloniales como Huelva (González de Canales et al. 2004: fig. 38) o la necrópolis de la Loma de Boliche (Siret 1908: 433, fig. 36), entre otros. Se trata de prototipos puramente orientales que llegan a la península Ibérica mediante la colonización fenicia y acaban por arraigar entre las comunidades autóctonas, como se aprecia a partir de los tres brazaletes identificados en la necrópolis de Les Moreres (González Prats 2002: 250, fig. 192) o de su presencia en diversas necrópolis del NE peninsular durante la primera mitad del s. VI a.C. (González Prats 2014a: 259). No obstante, uno de los individuos de Los Casarejos cuenta con los extremos en forma de cabeza de serpiente, con los ojos, la boca y el arranque de las escamas del cuerpo marcados (fig. 9, detalle), siendo un elemento distintivo que no se ha localizado en otros ejemplares ibéricos hasta el momento.

Por todo ello, en el marco territorial que durante la segunda mitad del s. VI a.C. se dio en el SE ibérico, parece posible plantear que el asentamiento de Los Casarejos responde a una ocupación puntual de una comunidad en tránsito que persigue alejarse de las principales vías de contacto, aunque ello le lleve a emplazarse en un lugar poco apto para vivir. Incluso cabe la posibilidad de plantear la naturaleza ganadera de este grupo, actividad más proclive para el entorno del asentamiento y el marco climático del período.

Pero tales circunstancias no impidieron a esta comunidad continuar participando de los circuitos económicos y comerciales de la época, algo para lo que seguro fue esencial que en el asentamiento se encontrasen determinados miembros de una élite que, además, fue capaz de adquirir o mantener ciertos bienes de prestigio como los brazaletes acorazonados. Así, a diferencia de otros traslados directos - de las ocupaciones del Corneros a La Parroquia o de Fonteta a El Oral-, Los Casarejos se constituye como un punto intermedio en un desplazamiento del que no conocemos el punto de origen ni el de destino de esta comunidad, pero que es fundamental para comprender la variabilidad de situaciones y respuestas que experimentaron los grupos del Hierro Antiguo al final de este período. De esta manera, la aparición de un asentamiento de corta duración revela la importancia que los traslados poblacionales tuvieron que tener durante esta época y pone de manifiesto la capacidad de resiliencia de estas comunidades para enfrentarse a las nuevas coyunturas que acabarían desembocando en la configuración de un nuevo paradigma sociocultural bajo la cultura Ibérica.

\section{CONSIDERACIONES FINALES}

La revisión exhaustiva del yacimiento arqueológico de Los Casarejos y su registro material ha permitido reubicar este asentamiento en la coyuntura histórica a la que corresponde, así como presentar una actualización fundamental que corrige gran parte de lo planteado hasta ahora sobre este enclave. El enfoque desarrollado durante este trabajo ha permitido aunar el análisis de la propia secuencia del yacimiento y su repertorio vascular, con las dinámicas territoriales y movimientos poblacionales que se dieron a nivel regional. Una lectura multiescalar que ha 
permitido empezar a cuestionarnos sobre la propia idiosincrasia de un asentamiento que por el momento se constituye en un unicum dentro de los patrones de asentamiento identificados en la región.

La posibilidad de que una comunidad se desplace desde algún punto probablemente mejor conectado, quizás desde el valle del Guadalentín, para instalarse en una posición agreste y alejada de las principales rutas de comunicación pone de manifiesto las dificultades que se pudieron dar en este periodo de inestabilidad. Sin embargo, ese traslado poblacional y la elección por una zona retirada no implicó un aislamiento de las principales corrientes comerciales del período, tal y como se desprende de la llegada de determinadas importaciones cerámicas. Una situación significativa que podría estar en línea con la existencia de algún personaje con cierto poder -o que al menos lo había tenido- como se desprende del hallazgo de los brazaletes de bronce, bienes de prestigio apenas identificados por el momento entre las comunidades autóctonas de la región. Así, Los Casarejos se define como una imagen fija de esta transición que apenas empezamos a conocer; una comunidad en movimiento de un territorio a otro, pero también en tránsito de un orden socioeconómico y cultural a punto de desaparecer hacia otro emergente que desembocará en la configuración de la cultura ibérica.

\section{AGRADECIMIENTOS}

Esta investigación se enmarca dentro de los resultados de un proyecto predoctoral financiado por el Plan Propio de la Universidad de Murcia. Quisiera agradecer el trato recibido en el Museo Arqueológico de Lorca tanto por sus técnicos, Andrés Martínez y Juana Ponce, como por el resto del personal de la institución durante mis estancias de investigación en el Museo. También me gustaría dar las gracias a José Ángel Zamora por las indicaciones dadas sobre las marcas incisas sobre paredes de ánfora de Los Casarejos.

\section{BIBLIOGRAFÍA}

ABAD, L.; SALA, F. (1993): El poblado ibérico de El Oral (San Fulgencio, Alicante), Valencia.

ABAD, L.; SALA, F. (2001): Poblamiento ibérico en el Bajo Segura. El Oral (II) y La Escuera, Madrid.

ÁLVAREZ, N.; CASTELLÓ, J. S.; GÓMEZ BELLARD, C. (2000): Estudio preliminar de las ánforas del Alt de Benimaquía (Denia, Alicante), QPAC 21, 121-136.
ARANCIBIA ROMÁN, A.; MORA SERRANO, B.; SÁEZ ROMERO, A. (2021): Malaka in the 5th century BC: a major punic port-city in the east of the "Circuit of Gadir", Il Mediterraneo Occidentale dalla fase fenicia all'egemonia cartaginese. Dinamiche insediative, forme rituali e cultura materiale nel V secolo a.C. (A. Roppa, M. Botto, P. van Dommelen, coords.), Roma, 265-284.

ARTEAGA, O.; SERNA, A. (1975): Los Saladares-71, NAH 3, $7-140$.

ASTRUC, M. (1951): La necrópolis de Villaricos, Informes y Memorias 28, Madrid.

AUBET, M. E. (2009): Tiro y las colonias fenicias de Occidente, Tercera edición actualizada y ampliada, Barcelona.

AUBET, M. E.; CARMONA, P.; CURIÀ, E.; DELGADO, A.; FERNÁNDEZ CANTOS, A.; PÁRRAGA, M. (1999): Cerro del Villar. I, El asentamiento fenicio en la desembocadura del río Guadalhorce y su interacción con el hinterland, Sevilla.

CAÑAVATE, V.; SALA, F.; LÓPEZ PRECIOSO, F. J.; NOVAL, R. (2017): Los Almadenes y la cuenca del río Mundo, un modelo de paisaje cultural para la protohistoria albacetense, El Oriente de Occidente. Fenicios y púnicos en el área ibérica (F. Prados, F. Sala, coords.), Alicante, 105-128.

CÁRCELES, E.; GALLARDO, J.; RAMOS, F. (2011): Excavaciones urbanas en Lorca: solar esquina calle Álamo con Núñez de Arce (santuario ibérico de tipo orientalizante), Verdolay 13, 71-81.

CÁRCELES, E.; SOLER, A.; LÓPEZ SÁNCHEZ, C. (2015): Restos singulares de un nuevo templo ibérico en Lorca (Murcia), Anales de Prehistoria y Arqueología 31, 117-130.

CELA, X. (2006): Las cerámicas ibéricas del Ibérico Antiguo (siglos VI-V a.C.): estado de la cuestión y propuestas, De les comunitats locals als estats arcaics: la formació de les societats complexes a la costa del Mediterrani occidental (M. C. Belarte, J. Sanmartí, eds.), Barcelona, 221-261.

CHAPA, M. T.; GONZÁLEZ REYERO, S.; ALBA, M. (2019): Los leones de El Macalón (Nerpio, Albacete): monumento, ideología y control territorial en la formación del mundo ibérico, Complutum 30 (2), 367-390.

DOI: https://doi.org/10.5209/cmpl.66338

CORREA, C. (2010): Memoria de las actuaciones arqueológicas realizadas en El Canal (El Saladillo, Mazarrón, Murcia), Memorias de Arqueología de la Región de Murcia 15, 129-147.

CUTILLAS, B. (2016): La Torre de Sancho Manuel: un asentamiento del Hierro Antiguo en la llanura del campo lorquino, Alberca 14, 53-69.

CUTILLAS, B. (2018): En busca de los pobladores de la Primera Edad del Hierro en el Campo de Cartagena: resultados preliminares en torno a la ocupación del Cabezo Ventura (Sureste ibérico), Lucentum 37, 75-91. DOI: https://doi.org/10.14198/LUCENTUM2018.37.04

CUTILLAS, B. (2019): El ajuar cerámico de una unidad rural del Hierro Antiguo: el caso de La Torre de Sancho Manuel 


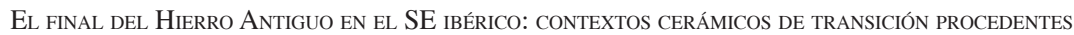
del asentamiento de Los Casarejos (Lorca, Murcia)

(Lorca, R. de Murcia), Opera Fictiles. Estudios transversales sobre cerámicas antiguas de la península ibérica (J. Coll, coord.), Valencia, 11-26.

CUTILLAS, B.; NAVARRO, M. (2018): Dos nuevas esfinges del poblado protohistórico de El Macalón (Nerpio, Albacete) localizadas en el Museo Arqueológico de Cartagena, Sagvntvm-PLAV 50, 255-260.

DOI: https://doi.org/10.7203/SAGVNTVM.50.12962

CUTILLAS, B.; ROS, M. M. (2020): Asentamientos polinucleares y resiliencia urbana entre el Bronce Final y la Edad del Hierro en el Sureste ibérico: nuevos datos a partir del Castellar de Librilla, Complutum 31 (1), 71-96.

DOI: https://doi.org/10.5209/cmpl.71650

DEUS, M. DE; ANTUNES, A.; MONGE, A. M. (2010): A Salsa 3 (Serpa) no contexto dos povoados abertos do Bronze Final do Sudoeste, IV Encuentro de Arqueología del Suroeste Peninsular (J. A. Pérez, E. Romero, eds.), Huelva, 515-523.

ELAYI, J. (2011): Inscripciones fenicias y marcas varias, La Fonteta. Excavaciones de 1996-2002 en la colonia fenicia de la actual desembocadura del río Segura (A. González Prats, coord.), Alicante, 259-290.

ELAYI, J. (2013): Histoire de la Phénicie, París.

ESQUEMBRE, M. A.; ORTEGA, J. R. (2017): El poblado fortificado del Castellar (Villena, Alicante), El Oriente de Occidente. Fenicios y púnicos en el área ibérica (F. Prados, F. Sala, coords.), Alicante, 129-154.

FRANKESTEIN, S. (1997): Arqueología del colonialismo. El impacto fenicio y griego en el sur de la Península Ibérica y el suroeste de Alemania, Barcelona.

GARCÍA BORJA, P.; CARRIÓN, Y.; COLLADO, I.; MONTERO, I.; MUÑOZ, M.; PÉREZ JORDÁ, G.; ROLDÁN, C.; ROMAN, D.; TORMO, C.; VERDASCO, C.; VIVESFERRÁNDIZ, J. (2010): Campaña de excavación arqueológica de urgencia en Caramoro II (Elx, Alacant), MARQ. Arqueología y Museos 4, 37-66.

GARCÍA BORJA, P.; VERDASCO, C.; MUÑOZ, M.; CARRIÓN, Y.; PÉREZ JORDÁ, G.; TORMO, C.; TRELIS, J. (2007): Materiales arqueológicos del Bronce Final aparecidos junto al Barranc del Botx (Crevillent, Alacant), Recerques del Museu d'Alcoi 16, 89-112.

GARCÍA CANO, J. M.; INIESTA, A. (1987): Excavaciones arqueológicas en el Cabezo de la Rueda (Alcantarilla). Campaña de 1981, Excavaciones y prospecciones arqueológicas en la Región de Murcia, Murcia, 134-175.

GARCÍA MARTÍNEZ, M. S.; ROS, M. M. (2010): Gestión del combustible leñoso e impacto medioambiental asociados a la metalurgia protohistórica de Punta de Los Gavilanes (Mazarrón, Murcia), TP 67, 545-559.

DOI: https://doi.org/10.3989/tp.2010.10055

GONZÁLEZ DE CANALES, F.; SERRANO, L.; LLOMPART, J. (2004): El emporio fenicio precolonial de Huelva, ca.900770 a.C., Madrid.
GONZÁLEZ PRATS, A. (1979): La tipología cerámica del horizonte II de Crevillente, Sagvntvm-PLAV 14, 59-96.

GONZÁLEZ PRATS, A. (1983): Estudio Arqueológico del poblamiento antiguo de la Sierra de Crevillente (Alicante), Anejo I de Lucentum, Alicante.

GONZÁLEZ PRATS, A. (1990): Nueva Luz sobre la protohistoria del Sudeste, Alicante.

GONZÁLEZ PRATS, A. (2002): La necrópolis de cremación de Les Moreres (Crevillente, Alicante, España) (s. IX-VII a.C.), Alicante.

GONZÁLEZ PRATS, A. (Coord.) (2011): La Fonteta. Excavaciones de 1996-2002 en la colonia fenicia de la actual desembocadura del río Segura (Guardamar del Segura, Alicante), Alicante.

GONZÁLEZ PRATS, A. (Coord.) (2014a): La Fonteta, 1. Estudio de los materiales arqueológicos hallados en la colonia fenicia de la actual desembocadura del río Segura (Guardamar del Segura, Alicante). Tomo 1, Alicante.

GONZÁLEZ PRATS, A. (Coord.) (2014b): La Fonteta, 2. Estudio de los materiales arqueológicos hallados en la colonia fenicia de la actual desembocadura del río río Segura (Guardamar del Segura, Alicante). Tomo 2, Alicante.

GRAU, I.; SEGURA, J. M. (2013): El Puig en sus inicios: del período orientalizante a la época plena, $E l$ oppidum ibérico de $E l$ Puig d'Alcoi: asentamiento y paisaje en las montañas de la Contestania (I. Grau, J. M. Segura, eds.), Alcoi, 67-110.

JIMÉNEZ ÁVILA, J. (2002): La toréutica orientalizante en la Península Ibérica, Madrid.

LÓPEZ CASTRO, J. L.; MARTÍNEZ, V.; MOYA, L.; PARDO, C. (2011): Baria I. Excavaciones de urgencia en Villaricos. La excavación de urgencia de 1987, Almería.

LÓPEZ CASTRO, J. L.; MARTÍNEZ, V.; PARDO, C. (2010): La ciudad de Baria y su territorio, Mainake 32 (1), 109-132.

LÓPEZ CASTRO, J. L.; PARDO, C.; MOYA, L. (2017): ¿Fondos de cabaña o depósitos rituales? Sobre un tipo de contextos materiales del Bronce Final y comienzos de la Edad del Hierro en el sur de la Península Ibérica. El depósito de Cortijo Riquelme (Almería), Zephyrus 80 (2): 69-91.

DOI: https://doi.org/10.14201/zephyrus2017806991

LÓPEZ MONDÉJAR, L. (2012): Poblamiento, sociedad y economía en el valle del Guadalentín: el cerro del Castillo de Lorca entre los siglos V a.C. - I d.C., Complutum 23 (1), 145-163. DOI: https://doi.org/10.5209/rev_Cmpl.2012.v23.n1.39535

LÓPEZ MONDÉJAR, L. (2015): Una aproximación a los espacios sagrados en el conjunto ibérico de Lorca (Murcia) entre los períodos ibérico y romano: problemas y perspectivas de trabajo, El tiempo final de los santuarios ibéricos en los procesos de impacto y consolidación del mundo romano (T. Tortosa, S.F. Ramallo, coords.), Madrid, 117-133.

LÓPEZ ROSENDO, E. (2009): Intervención arqueológica urgente en el yacimiento de Los Villares de Jerez de la Frontera (Cádiz). Campaña 2004, Anuario Arqueológico de Andalucía 2004, Sevilla, 369-378. 
LORRIO, A. (2008): Qurénima: el Bronce Final del sureste de la Península Ibérica, Madrid.

LORRIO, A.; PERNAS, S.; TORRES, M. (2016): Puntas de flecha orientalizantes en contextos urbanos del Sureste de la Península Ibérica: Peña Negra, La Fonteta y Meca, $\mathrm{Cu}$ PAUAM 42, 9-78.

DOI: https://doi.org/10.15366/cupauam2016.42.001

LORRIO, A.; PERNAS, S.; TORRES, M.; TRELIS, J.; CAMACHO, P.; CASTILLO, L. (2020): Peña Negra (Crevillent, Alicante): la ciudad orientalizante de Herna y su territorio, Actas del IX Congreso Internacional de Estudios Fenicios y Púnicos. Un viaje entre el Oriente y el Occidente del Mediterráneo (S. Celestino, E. Rodríguez, eds.), Mérida, 521-540.

MANCHA, S.; LEÓN, L. M. (2009): Memoria final de excavación arqueológica de urgencia sobre el trazado del gasoducto conexión a Lorca entre los vértices v-90 y v-91 en el término municipal de Lorca, Memoria de Intervención Inédita depositada en la Dirección General de Bienes Culturales de la Comunidad Autónoma de la Región de Murcia.

MANCHA, S. (2010): El yacimiento arqueológico del Hierro antiguo de Los Casarejos (Lorca, Murcia), Alberca 8, 41-60

MANSEL, K. (2000): Los hallazgos de metal procedentes del horizonte fenicio más antiguo B1 del Morro de Mezquitilla (Algarrobo, Málaga), IV Congreso Internacional de Estudios Fenicios y Púnicos (M. Barthélemy, M.E. Aubet, coords.), Cádiz, 1601-1614.

MARTÍN CÓRDOBA, E.; RAMÍREZ, J. D.; RECIO, A. (2006): Producción alfarera fenicio-púnica en la costa de VélezMálaga (siglos VIII-V a.C.), Mainake 27, 257-287.

MARTÍN RUIZ, J. A. (2007): La crisis del siglo VI a.C. en los asentamientos fenicios de Andalucía, Málaga.

MARTÍNEZ, M. (2006). Excavación arqueológica en la zona de La Alberca (Lorca, Murcia). Un horno alfarero de los siglos VII-VI a.C. y un centro comercial y militar de época tardopúnica y romana, Memorias de Arqueología de la Región de Murcia 14, 213-260.

MATA, C.; BONET, H. (1992): Cerámica ibérica: ensayo de tipología, Estudios de Arqueología Ibérica y Romana. Homenaje a Enrique Pla Ballester, Valencia, 117-175.

MATA, C.; SORIA, L. (1997): Marcas y grafitos sobre contenedores ibéricos, APL 22, 297-374.

ORTIZ, R. (2014): La cerámica a mano, La Fonteta, 1. Estudio de los materiales arqueológicos hallados en la colonia fenicia de la actual desembocadura del río Segura (Guardamar del Segura, Alicante). Tomo 1 (A. González, Coord.), Alicante: 13-238.

PAPI, C. (1992-1994): Improntas de esterillas en cerámicas del Bronce Final de Peña Negra (Crevillente, Alicante). Campañas de 1983 y 1984, Lucentum 11-13, 39-49.

PEÑA, J. L.; ENRIQUE, M.; GRAU, E.; MARTÍ, M. A. (1996): El poblado de la Mola d'Agres, Homenaje a Milagros GilMascarell Boscà, Valencia.
PLA, R. (2014): Las tinajas (tipo 43), La Fonteta, 2. Estudio de los materiales arqueológicos hallados en la colonia fenicia de la actual desembocadura del río Segura (Guardamar del Segura, Alicante). Tomo 2 (A. González, Coord.), Alicante, 691-728.

RAMON, J. (1995): Las ánforas fenicio-púnicas del Mediterráneo Central y Occidental, Barcelona.

RAMON, J.; SÁEZ, A.; SÁEZ, A. M.; MUÑOZ, A. (2007): El taller alfarero tardoarcaico de Camposoto (San Fernando, Cádiz), Sevilla.

RODERO, A.; PEREA, A.; CHAPA, T.; PEREIRA, J.; MADRIGAL, A.; PÉREZ-DIE, M. (1996): La necrópolis de Villaricos (Almería), Homenaje al Profesor Manuel FernándezMiranda (M. A. Querol, T. Chapa), Madrid, 373-383.

ROS, M. M. (1986-1987): El poblado de Santa Catalina del Monte: una aproximación a la urbanística del siglo VI a.C. en el ámbito territorial del eje Segura-Guadalentín, Cuadernos de Prehistoria y Arqueología 13-14, 77-88.

ROS, M. M. (1989): Dinámica urbanística y cultura material del Hierro Antiguo en el Valle del Guadalentín, Murcia.

ROS, M. M. (1990): Datos para una definición del Bronce Final Pleno en el Altiplano Yecla-Jumilla: las cazuelas carenadas de Coimbra del Barranco Ancho (Jumilla), TP 47, 351-362.

ROS, M. M. (2017): Nuevos datos en torno a la presencia fenicia en la Bahía de Mazarrón (Sureste Ibérico), El Oriente de Occidente. Fenicios y púnicos en el área ibérica (F. Prados, F. Sala, coords.), Alicante, 79-104.

ROS, M. M.; BROTONS, F.; RAMALLO, S. F. (2016): Aproximación al horizonte preibérico - ibérico antiguo en el noroeste murciano: la prospección del oppidum de Los Villares del Estrecho de las Cuevas de la Encarnación (Caravaca de la Cruz), Homenaje a la profesora Concepción Blasco Bosqued, Anejos de CuPAUAM 2, Madrid, 219-239.

ROS, M. M.; CUTILlAS, B. (2020): De Fenicios a Púnicos en la Bahía de Mazarrón: el registro de las ánforas T-11 en el promontorio costero de Punta de los Gavilanes, Actas del IX Congreso Internacional de Estudios Fenicios y Púnicos. Un viaje entre el Oriente y el Occidente del Mediterráneo (S. Celestino, E. Rodríguez, eds.), Mérida, 801-816.

ROUILLARD, P.; GAILLEDRAT, E.; SALA, F. (2007): L'établissement protohistorique de La Fonteta (fin VIIIe - VIe siècle av. J.-C.), Madrid.

RUIZ GIL, J. A.; LÓPEZ AMADOR, J. J. (2001): Formaciones sociales agropecuarias en la Bahía de Cádiz, 5000 años de adaptación ecológica en la Laguna del Gallo (El Puerto de Santa María), Sanlúcar de Barrameda.

RUIZ MATA, D.; VALLEJO, J. I. (2002): Continuidad y cambio durante el siglo VI a.C. Las cerámicas del corte C del Cerro Macareno (La Rinconada, Sevilla), Spal 11, 197-218.

SALA, F. (2010): Nuevas perspectivas sobre las relaciones púnicas con la costa ibérica del sureste peninsular, Mainake 32 (2), 933-950. 
SALA, F.; LÓPEZ PRECIOSO, J.; NOVAL, R.; CAÑAVATE, V.; CARRATALÁ, I.; FERNÁNDEZ, S.; PERDIGUERO, P.; ROSELL, P. (2020): Los Almadenes (Hellín, Albacete) o la meta de un sistema productivo y comercial del siglo VI a.C. a través del río Segura, Actas del IX Congreso Internacional de Estudios Fenicios y Púnicos. Un viaje entre el Oriente y el Occidente del Mediterráneo (S. Celestino, E. Rodríguez, eds.), Mérida, 837-848.

SÁNCHEZ GONZÁLEZ, M. J.; MEDINA, A. J.; SÁNCHEZ GONZÁLEZ, M. B. (2010): Prospecciones arqueológicas sistemáticas en el valle del Río Vélez o Río Corneros (Lorca, Murcia), Memorias de Arqueología de la Región de Murcia 15, 1125-1176.

SIRET, L. (1908): Villaricos y Herrerías. Antigüedades púnicas, romanas, visigóticas y árabes, Madrid.

SORIA, L.; MATA, C. (2015): Marcas y epígrafes sobre ánforas de época ibérica. II, Lucentum 34, 145-171. DOI: https://doi.org/10.14198/LVCENTVM2015.34.05

SORIANO, S.; JOVER, F. J.; LÓPEZ SEGUÍ, E. (2012): Sobre la fase orientalizante en las tierras meridionales valencianas: el yacimiento de Casa de Secà (Elche, Alicante) y la dinámica del poblamiento en el Sinus Ilicitanus, Sagvntvm-PLAV 44, 77-97.

DOI: https://doi.org/10.7203/ SAGVNTVM.44.1772

SUÁREZ, J.; MÁRQUEZ, J. E. (2014): La problemática de los fondos de cabaña en el marco de la arquitectura protohistórica del sur de la Península Ibérica, Menga 5, 199-225.

VAN DOMMELEN, P. (1998): On colonial grounds: a comparative study of colonialism and rural settlement in first millennium BC west central Sardinia, Leiden.

VIVES-FERRÁNDIZ, J. (2005): Negociando encuentros: situaciones coloniales e intercambios en la costa oriental de la Península Ibérica (ss. VIII-VI a.C.), Cuadernos de Arqueología Mediterránea 12, Barcelona.

ZAMORA, J. A. (2019): Poenica Hispana II: Documentos epigráficos fenicio-púnicos inéditos, mal conocidos o sujetos a nuevo examen procedentes de la Península Ibérica y su entorno, Orientalística en tiempos difíciles: actas del VII Congreso Nacional del Centro de Estudios del Próximo Oriente (J. Gil, A. Mederos), Zaragoza, 377-400. 